\title{
Synthesis, Crystal Structures and Photoluminescent Properties of One-Dimensional Europium(III)- and Terbium(III)-Glutarate Coordination Polymers, and Their Applications for the Sensing of $\mathrm{Fe}^{3+}$ and Nitroaromatics
}

OPEN ACCESS

Edited by:

Sidney J. L. Ribeiro,

São Paulo State University, Brazil

Reviewed by:

Joulia Larionova,

Université Montpellier 2, France

Lippy Faria Marques,

Governo do Estado do Rio de

Janeiro, Brazil

${ }^{*}$ Correspondence:

Sajjad Hussain

sajjaduet07@yahoo.com

Xuenian Chen

xnchen@htu.edu.cn

Specialty section:

This article was submitted to

Inorganic Chemistry,

a section of the journal

Frontiers in Chemistry

Received: 28 June 2019 Accepted: 11 October 2019 Published: 05 November 2019

Citation:

Hussain S, Chen X, Harrison WTA,

Elsegood MRJ, Ahmad S, Li S, Muhammad S and Awoyelu D (2019)

Synthesis, Crystal Structures and

Photoluminescent Properties of

One-Dimensional Europium(III)- and

Terbium(III)-Glutarate Coordination

Polymers, and Their Applications for

the Sensing of $\mathrm{Fe}^{3+}$ and

Nitroaromatics. Front. Chem. 7:728

doi: 10.3389/fchem.2019.00728

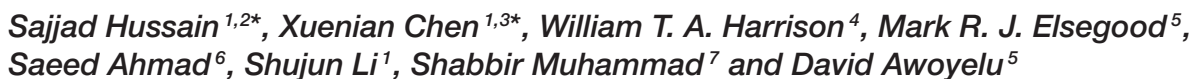

${ }^{1}$ Henan Key Laboratory of Boron Chemistry and Advanced Energy Materials, School of Chemistry and Chemical Engineering, Henan Normal University, Xinxiang, China, ${ }^{2}$ Department of Chemistry, Mohi-Ud-Din Islamic University, Azad Jammu and Kashmir, Pakistan, ${ }^{3}$ College of Chemistry and Molecular Engineering, Zhengzhou University, Zhengzhou, China, ${ }^{4}$ Department of Chemistry, University of Aberdeen, Aberdeen, United Kingdom, ${ }^{5}$ Chemistry Department, Loughborough University, Loughborough, United Kingdom, ${ }^{6}$ Department of Chemistry, College of Sciences and Humanities, Prince Sattam Bin Abdulaziz University, Al-Kharj, Saudi Arabia, ${ }^{7}$ Department of Physics, College of Science, King Khalid University, Abha, Saudi Arabia

Two lanthanide-glutarate coordination polymers, viz. : $\left\{\left[\mathrm{Eu}\left(\mathrm{C}_{5} \mathrm{H}_{6} \mathrm{O}_{4}\right)\left(\mathrm{H}_{2} \mathrm{O}\right)_{4}\right] \mathrm{Cl}\right\}_{n}$, (1) and $\left[\mathrm{Tb}\left(\mathrm{C}_{5} \mathrm{H}_{7} \mathrm{O}_{4}\right)\left(\mathrm{C}_{5} \mathrm{H}_{6} \mathrm{O}_{4}\right)\left(\mathrm{H}_{2} \mathrm{O}\right)_{2}\right]_{n}$, (2) have been synthesized and characterized by $\mathbb{R}$ spectroscopy, thermogravimetric analysis, and X-ray crystallography. In 1, the $\mathrm{Eu}$ (III) ions are coordinated by four $\mathrm{O}$ atoms from two bidentate chelating carboxylate groups, one $\mathrm{O}$ atom from a bridging carboxylate group and four $\mathrm{O}$ atoms from water molecules adopting an $\mathrm{EuO}_{9}$ distorted tri-capped trigonal prismatic coordination geometry. In $\mathbf{2}$, the $\mathrm{Tb}$ (III) ions are coordinated by six $\mathrm{O}$ atoms from three bidentate chelating carboxylates, one $\mathrm{O}$ atom from a bridging carboxylate and two $\mathrm{O}$ atoms from water molecules to generate distorted tri-capped trigonal prismatic $\mathrm{TbO}_{9}$ polyhedron. In both compounds, the metal polyhedra share edges, producing centrosymmetric $\mathrm{Ln}_{2} \mathrm{O}_{2}$ diamonds, and are linked into [001] chains by bridging glutarate di-anions. The crystal structures are consolidated by $\mathrm{O}-\mathrm{H} \ldots \mathrm{O}$ and $\mathrm{O}-\mathrm{H} \ldots \mathrm{Cl}$ hydrogen bonds in 1, and $\mathrm{O}-\mathrm{H} \ldots \mathrm{O}$ hydrogen bonds in 2. Compound $\mathbf{1}$ exhibits a red emission attributed to the ${ }^{5} D_{0} \rightarrow{ }^{7} F_{J}(J=$ 1-4) transitions of the Eu(III) ion, whereas 2 displays green emission corresponding to the ${ }^{5} D_{4} \rightarrow{ }^{7} F_{J}(J=0-6)$ transitions of the $\mathrm{Tb}(I I I)$ ion. Both the compounds exhibit high sensitivity and selectivity for $\mathrm{Fe}^{3+}$ ions due to luminescence quenching compared with other metal ions, which include; $\mathrm{Na}^{+}, \mathrm{Mg}^{2+}, \mathrm{Al}^{3+}, \mathrm{Cr}^{3+}, \mathrm{Mn}^{2+}, \mathrm{Fe}^{2+}, \mathrm{Co}^{2+}, \mathrm{Ni}^{2+}$, $\mathrm{Zn}^{2+}$ and $\mathrm{Cd}^{2+}$. Compounds $\mathbf{1}$ and $\mathbf{2}$ also show high luminescence quenching sensitivity for 4-nitrophenol over the other aromatic and nitroaromatic compounds, namely; bromobenzene, 1,3-dimethylbenzene, nitrobenzene, 4-nitrotolune, 4-nitrophenol, 2,6dinitrophenol and 2,4,6-trinitrophenol.

Keywords: europium(III), terbium(III), glutarate, X-ray structure, luminescence, sensors 


\section{INTRODUCTION}

Lanthanide coordination compounds have attracted great interest from the scientific community in the last two decades due to their potential as an emerging type of multifunctional luminescent materials in areas such as telecommunications, optical amplifiers, immunoassays, and sensors (Werts, 2005; Binnemans, 2009; Armelao et al., 2010; Bünzli, 2010, 2015; Zhang et al., 2010; Azab et al., 2013; Feng and Zhang, 2013; Heffern et al., 2013; Xiang et al., 2017). They exhibit unique optical properties, such as large Stokes, shift, characteristic narrow line-like emission bands, and long lived excited state lifetimes resulting from intra configurational $4 f-4 f$ transitions (Werts, 2005; Allendorf et al., 2009; Armelao et al., 2010; Bünzli, 2010, 2015; Feng and Zhang, 2013; Heffern et al., 2013; Räsänen et al., 2014; Xiang et al., 2017). The luminescent nature of lanthanide coordination compounds is associated with the organic ligand moieties and lanthanide centers (Xiang et al., 2017). Due to the low molar extinction coefficient of the Laporte forbidden $f-f$ transitions, the direct photoexcitation of the lanthanide ions becomes difficult (Werts, 2005; Armelao et al., 2010; Bünzli, 2010, 2015; Heffern et al., 2013; Xiang et al., 2017). The introduction of suitable linkers (ligands) provides an alternative pathway for energy transfer and enriches the lanthanide emitting levels. These ligands transfer energy from the excited triplet state of ligand to the lowest emitting level of the lanthanide ion. The lanthanide ion then relaxes to the ground state by emission of energy (Reinhard and Güdel, 2002; Werts, 2005; Allendorf et al., 2009; Azab et al., 2013; Heffern et al., 2013; Rao et al., 2013; Räsänen et al., 2014; Bünzli, 2015; Xiang et al., 2017). The luminescent properties are not only related to the composition of the materials, but are also heavily dependent on the structure and intermolecular packing for their energy transfer (Cui et al., 2011; Xiang et al., 2017). Choosing appropriate ligands to increase the excited state lifetime and quantum yield (the light output) of lanthanide(III) complexes is thus essential for the development of improved luminescent materials (Li and Yan, 2012). In this regard, aromatic carboxylic acids such as, terephthalic acid (Daiguebonne et al., 2008; Wang et al., 2012) benzene-carboxylic acids (Yan et al., 2005; Wang et al., 2010b, 2012; Zhuravlev et al., 2011; Gai et al., 2013), and pyridine-dicarboxylic acid (Reinhard and Güdel, 2002; Huang et al., 2008; Zhu et al., 2009; Song et al., 2016; Xiang et al., 2017; Kumar et al., 2018) have been particularly used to design luminescent lanthanide coordination polymers. A number of studies also exist on the complexes of aliphatic carboxylic acids such as, malonic acid (Hussain et al., 2019), succinic acid (Cui et al., 2005; De Oliveira et al., 2013), glutaric acid (Głowiak et al., 1987; Legendziewicz et al., 1999; Antic-Fidancev et al., 2002), and adipic acid (Wang et al., 2010b).

From the large number of lanthanide coordination polymers, only some of them have been found active and explored for luminescence changes when brought in contact with some analyte or target molecules, possessing promising application as chemical sensors (Zhao et al., 2004; Zhang et al., 2010; Azab et al., 2013; Wang et al., 2014; Xiang et al., 2017). Thus, the optical properties of lanthanides are a beneficial tool to design new lanthanide based sensors, such as sensing of temperature (Miyata et al., 2013; Rao et al., 2013), cations (Zhao et al., 2004, 2014a; Chen et al., 2009; Zhang et al., 2010; Bogale et al., 2016, 2017a), anions (Wong et al., 2006; Tan and Wang, 2011) nitroaromatics (Bogale et al., 2016, 2017a) and small molecules (Zhou et al., 2013; Zhao et al., 2014b). Such developments also encouraged us to synthesize new lanthanide coordination polymers with characteristic properties to selectively recognize and sense the specific analyte. Particularly, we are interested to develop a highly effective, quick, and reliable method for the detection of iron and nitroaromatics because of their essentiality in health care and high toxicity/explosiveness, respectively.

Among the luminescent lanthanide complexes, those of europium(III) and terbium(III) (emitting red and green light, respectively) have been especially widely studied because of their efficient luminescent properties (Cui et al., 2005; Bangaru et al., 2010; Tsaryuk et al., 2010; Zhuravlev et al., 2011; Hussain et al., 2019). To further explore the luminescent behavior of such complexes and as a part of our ongoing research on lanthanide complexes (Hussain et al., 2014, 2015a,b, 2018, 2019) herein, we report the structural characterization and photoluminescent properties of two one-dimensional $\mathrm{Eu}(\mathrm{III})$ and $\mathrm{Tb}$ (III) coordination polymers based on the glutarate ligand. In addition, the possible use of these complexes as sensors for detection of $\mathrm{Fe}^{3+}$ and 4-nitrophenol was investigated. Although the crystal structures of a number of lanthanide-glutarate complexes have been reported in the literature (Głowiak et al., 1987; Serpaggi and Férey, 1998; Legendziewicz et al., 1999; Benmerad et al., 2000; Antic-Fidancev et al., 2002; Bromant et al., 2005; Rahahlia et al., 2006; Wang et al., 2010a; Hussain et al., 2015a; Zehnder et al., 2018) the optical properties of only a few of them have been studied (Głowiak et al., 1987; Legendziewicz et al., 1999; Antic-Fidancev et al., 2002). However, the use of none of these has been explored previously for sensing purposes. Thus, the present study would be the first one describing the potential of lanthanide-glutarates for application as sensors. As the exploitation of the new synthetic methods, structures, and properties in this system is still interesting, therefore, the studies of new lanthanide complexes with glutaric acid are important from both fundamental and applied viewpoints.

\section{EXPERIMENTAL}

\section{Materials and Measurements}

The metals salts $\left(\mathrm{EuCl}_{3} \cdot 6 \mathrm{H}_{2} \mathrm{O}, \mathrm{TbCl}_{3} \cdot 6 \mathrm{H}_{2} \mathrm{O}\right)$ and ethanol were obtained from Alfa Aesar, USA. Glutaric acid was obtained from Merck Chemical Co. Germany. All other metal salts and nitroaromatics were purchased from Sigma Aldrich, a Johnson Matthey Company. Elemental analyses were carried out on a Varion Micro Cube, Elementar, Germany. FTIR spectra were recorded using $\mathrm{KBr}$ pellets on a Perkin Elmer FTIR 180 spectrophotometer over the wave number range from 4,000 to $250 \mathrm{~cm}^{-1}$. Thermal analyses were carried out under air with a continuous heating rate of $10^{\circ} \mathrm{C} \mathrm{min}^{-1}$ from room temperature to $1,000^{\circ} \mathrm{C}$ on thermo-gravimetric analyzer/differential scanning calorimeter model SDT Q 600 (TA Instruments, USA) by taking $10.459 \mathrm{mg}$ and $8.691 \mathrm{mg}$ of 
compound $\mathbf{1}$ and 2, respectively. The excitation and emission spectra were measured at room temperature in steady state mode using FLS 180 spectrophotometer equipped with Xenon Arc lamp, photomultiplier detector R928P and Czerny-Turner monochromators having focal length of $300 \mathrm{~mm}$. The excitation and emission were monitored between 250-400 and 400$800 \mathrm{~nm}$, respectively.

\section{Crystal Structure Determination}

The crystal data for compound $\mathbf{1}$ and $\mathbf{2}$ were collected on a Bruker Kappa Apex II CCD diffractometer using graphitemonochromated $\mathrm{MoK} \alpha$ radiation $(\lambda=0.71073 \AA)$ at a temperature $150 \mathrm{~K}$. The structures were solved by direct methods and the structural models were completed and optimized by refinement against $F^{2}$ with SHELX-2014 (Sheldrick, 2015). The aliphatic C-bound $\mathrm{H}$ atoms were geometrically placed and refined as riding atoms with $\mathrm{C}-\mathrm{H}=0.99 \AA$ and $U_{\text {iso }}(\mathrm{H})=1.2$ $U_{\text {eq }}(\mathrm{C})$. The water molecule $\mathrm{H}$ atoms were located in difference maps and coordinates were freely refined with the aid of mild geometrical restraints $\{$ target: $\mathrm{O}-\mathrm{H}=0.84 \AA$ \} and the isotropic atomic displacement parameters were fixed to $1.5 \times U_{\text {eq }}$ of the parent atom. The key crystallographic data and details of the structure refinements are provided in Table S1.

\section{Preparation of Complexes}

\section{Preparation of $\left\{\left[\mathrm{Eu}\left(\mathrm{C}_{5} \mathrm{H}_{6} \mathrm{O}_{4}\right)\left(\mathrm{H}_{2} \mathrm{O}\right)_{4}\right] \mathrm{Cl}\right\}_{\mathrm{n}}(1)$}

$\mathrm{EuCl}_{3} \cdot 6 \mathrm{H}_{2} \mathrm{O}(0.183 \mathrm{~g}, 0.5 \mathrm{mmol})$ was dissolved in $15 \mathrm{~mL}$ deionized water and glutaric acid $(0.132 \mathrm{~g}, 1.0 \mathrm{mmol})$ was dissolved in $25 \mathrm{~mL}$ ethyl alcohol. The solutions were mixed and stirred in a round-bottomed flask at room temperature for $3 \mathrm{~h}$. $1 \mathrm{M} \mathrm{NaOH}$ solution was used to adjust $\mathrm{pH} 5-6$ of the reaction mixture during stirring. The reaction mixture was filtered and left at room temperature for crystallization. Colorless block shape crystals of $\mathbf{1}$ appeared after 20 days. The crystals were recovered by vacuum filtration, rinsing with ethanol and drying in air. Yield: $51 \%$. Analysis for $\mathrm{C}_{5} \mathrm{H}_{14} \mathrm{O}_{8} \mathrm{ClEu}$ : calculated (\%): C 15.41; $\mathrm{H} 3.62$; found (\%): C 15.61; H 3.58.

\section{Preparation of $\left[\mathrm{Tb}\left(\mathrm{C}_{5} \mathrm{H}_{7} \mathrm{O}_{4}\right)\left(\mathrm{C}_{5} \mathrm{H}_{6} \mathrm{O}_{4}\right)\left(\mathrm{H}_{2} \mathrm{O}\right)_{2}\right]_{\mathrm{n}}$ (2)} $\mathrm{TbCl}_{3} \cdot 6 \mathrm{H}_{2} \mathrm{O}(0.189 \mathrm{~g}, 0.5 \mathrm{mmol})$ and glutaric acid $(0.132 \mathrm{~g}, 1$ mmol) were dissolved in $15 \mathrm{~mL}$ deionized water and $20 \mathrm{~mL}$ ethyl alcohol, respectively. The mixture was stirred at room temperature in a round bottomed flask for $4 \mathrm{~h} .1 \mathrm{M} \mathrm{NaOH}$ solution was added to adjust $\mathrm{pH} 4-5$ of the reaction mixture. The solution was filtered and left at room temperature for crystallization. After 3 weeks, colorless block shape crystals of 2 were recovered as described above. Yield: 47\%. Analysis for $\mathrm{C}_{10} \mathrm{H}_{17} \mathrm{O}_{10} \mathrm{~Tb}$ : calculated (\%) $\mathrm{C}$ 26.33; $\mathrm{H}$ 3.76; found (\%): C 26.45; H 3.83 .

\section{Photoluminescence Measurements}

To investigate the detection ability of $\mathbf{1}$ toward the selected metals ions; $\mathrm{Na}^{+}, \mathrm{Mg}^{2+}, \mathrm{Al}^{3+}, \mathrm{Cr}^{3+}, \mathrm{Mn}^{2+}, \mathrm{Fe}^{2+}, \mathrm{Fe}^{3+}, \mathrm{Co}^{2+}, \mathrm{Ni}^{2+}$, $\mathrm{Zn}^{2+}$ and $\mathrm{Cd}^{2+}$ (as chloride salts), equal volumes $(130 \mu \mathrm{L}$ of $1 \times 10^{-3} \mathrm{M}$ ) of metal solutions were added to 1 suspended in methanol $(0.3 \mathrm{mg} / 3 \mathrm{~mL})$. Likewise, the metal sensing aptitude of 2 was explored by adding equal volumes $\left(160 \mu \mathrm{L}, 1 \times 10^{-3}\right.$
M) of these metals to methanolic suspensions of $2(0.5 \mathrm{mg} /$ $3 \mathrm{~mL}$ ). Luminescence titration measurements were performed by stepwise addition of $\mathrm{Fe}^{3+}$ solution into $0.35 \mathrm{mg}$ of 1 and $0.51 \mathrm{mg}$ of 2 suspended in $3 \mathrm{~mL}$ of methanol. After ultrasonic treatment for $5 \mathrm{~min}$, their emission spectra were recorded under the same conditions at room temperature.

In the same way, to study the detection ability of $\mathbf{1}$ toward selected aromatics and nitro-aromatics including; bromobenzene (BB), 1,3-dimethylbenzene (DMB), nitrobenzene (NB), 4nitrotolune (4-NT), 4-nitrophenol (4-NP), 2,6-dinitrophenol (DNP), and 2,4,6-trinitrophenol (TNP), equal volumes (120 $\mu \mathrm{L})$ of the aromatics and nitroaromatics $(0.001 \mathrm{M}$ in ethanol) were added to $0.3 \mathrm{mg}$ of 1 suspended in $3 \mathrm{~mL}$ of methanol. Compound 2 was tested by adding $150 \mu \mathrm{L}(0.001 \mathrm{M}$ in ethanol) of these compounds to $0.5 \mathrm{mg}$ of 2 suspended in $3 \mathrm{~mL}$ methanol. The luminescence titration measurements on $1(0.3 \mathrm{mg} / 3 \mathrm{~mL}$ methanol) were done by stepwise addition $(5-160 \mu \mathrm{L})$ of 4 nitrophenol ( $0.001 \mathrm{M}$ in ethanol). In the same way, 2 was assessed by the gradual addition $(10-250 \mu \mathrm{L})$ of 4 -nitrophenol $(0.001 \mathrm{M}$ in ethanol) to $0.5 \mathrm{mg}$ of 2 suspended in $3 \mathrm{~mL}$ of methanol.

\section{RESULTS AND DISCUSSION}

\section{Synthesis}

The reaction of $\mathrm{EuCl}_{3} \cdot 6 \mathrm{H}_{2} \mathrm{O}$ or $\mathrm{TbCl}_{3} \cdot 6 \mathrm{H}_{2} \mathrm{O}$ with two equivalents of glutaric acid $\left(\mathrm{C}_{5} \mathrm{H}_{8} \mathrm{O}_{4}\right)$ in the presence of $\mathrm{NaOH}$ in water-ethanol medium yielded the colorless crystals of $\left\{\left[\mathrm{Eu}\left(\mathrm{C}_{5} \mathrm{H}_{6} \mathrm{O}_{4}\right)\left(\mathrm{H}_{2} \mathrm{O}\right)_{4}\right] \mathrm{Cl}\right\}_{n}, \quad$ (1) and $\left[\mathrm{Tb}\left(\mathrm{C}_{5} \mathrm{H}_{7} \mathrm{O}_{4}\right)\left(\mathrm{C}_{5} \mathrm{H}_{6} \mathrm{O}_{4}\right)\left(\mathrm{H}_{2} \mathrm{O}\right)_{2}\right]_{n}(2)$, respectively. The $\mathrm{pH}$ value of the medium seems to have a significant influence on the nature of final products. In the preparation of complex $\mathbf{1}$, where more amount of $\mathrm{NaOH}$ was added as base, the ligand was fully deprotonated to produce glutarate di-anions, while in case of 2, the lower $\mathrm{pH}$ resulted in the partial deprotonatation of the ligand and produced hydrogen-glutarate anion $\left(\mathrm{HGlut}^{-}\right)$. The proposed formulae of the complexes are in accordance with the elemental analysis. The complexes were further characterized by thermal analysis and X-ray crystallography.

\section{IR Spectroscopy}

The IR spectra of $\mathbf{1}$ and $\mathbf{2}$ are shown in Figures S1, S2, respectively. The IR spectra of both complexes are similar, each showing broad absorption bands in the region $3,400-3,100 \mathrm{~cm}^{-1}$ centered at 3,387 and $3,368 \mathrm{~cm}^{-1}$ for 1 and 2, respectively, which correspond to the $\mathrm{O}-\mathrm{H}$ stretching vibrations of water molecules. The sharp peaks at $1,696 \mathrm{~cm}^{-1}$ (with a shoulder at $1,646 \mathrm{~cm}^{-1}$ ) in case of 1 and at $1,695 \mathrm{~cm}^{-1}$ (with a shoulder at $1,640 \mathrm{~cm}^{-1}$ ) for 2 , cannot be assigned to the asym(COO) vibration as in the free acid, but represents the $\mathrm{O}-\mathrm{H}$ bending vibration due to the presence of strong $\mathrm{H}$-bonded water molecules (Rahahlia et al., 2007). The bands at 1,553 and $1,525 \mathrm{~cm}^{-1}$ for 1 and 1,555 and $1,527 \mathrm{~cm}^{-1}$ for 2 correspond to $\nu_{\text {asym }}(\mathrm{COO})$ vibrations, while those at 1,436 and $1,407 \mathrm{~cm}^{-1}$ for 1 and 1,437 and 1,403 $\mathrm{cm}^{-1}$ for 2 are associated with the corresponding symmetric modes (De Oliveira et al., 2013; Hussain et al., 2018, 2019). A difference $(\Delta \nu)$ of about $120 \mathrm{~cm}^{-1}$ in $\nu_{\text {asym }}\left(\mathrm{CO}_{2}\right)$ and $\nu_{\text {sym }}$ $\left(\mathrm{CO}_{2}\right)$ wavenumbers is indicative of the bidentate coordination 
of the carboxylate groups to the metal ions $\mathrm{Eu}(\mathrm{III})$ and $\mathrm{Tb}(\mathrm{III})$. For monodentate coordination of carboxylates, $\Delta v$ is usually more than $200 \mathrm{~cm}^{-1}$ (Deacon and Philips, 1980; Zhuravlev et al., 2011; Batool et al., 2015). Monodentate coordination removes the equivalence of two oxygen atoms. If the $\mathrm{C}-\mathrm{O}$ bond orders are appreciably affected, a pseudo-ester configuration is obtained. This decreases $v_{\text {sym }}\left(\mathrm{CO}_{2}\right)$ and increases $v_{\text {asym }}\left(\mathrm{CO}_{2}\right)$ as well as the separation $(\Delta v)$ between the $v\left(\mathrm{CO}_{2}\right)$ values relative to those for the free carboxylate ions, usually taken as sodium salts. Chelation or symmetrical bridging should not alter the bond orders and it has been suggested that bidentate coordination gives separation similar to the ionic values. For sodium and potassium acetates, the asymm and symm modes appear at $1,578-1,571 \mathrm{~cm}^{-1}$ and $1,414-1,402 \mathrm{~cm}^{-1}$, respectively, and the respective separations are 164 and $171 \mathrm{~cm}^{-1}$, respectively (Deacon and Philips, 1980). Thus, the coordination mode proposed for glutarate acid in $\mathbf{1}$ and $\mathbf{2}$ is through $O, O^{\prime}$-chelation of the carboxylate group. The weak bands appearing around $2,900 \mathrm{~cm}^{-1}$, can be assigned to the $\mathrm{C}-\mathrm{H}$ stretching vibration of the glutarate ligand. The medium band around $900 \mathrm{~cm}^{-1}$ is ascribed to bending vibration, $\delta(\mathrm{O}-\mathrm{C}-$ O) of the carboxylate group (Hussain et al., 2019). The spectra also give characteristic $\mathrm{C}-\mathrm{C}$ stretching vibrations of the glutaric group near $1,200 \mathrm{~cm}^{-1}$ (Rahahlia et al., 2007). For both 1 and 2 , the peaks in the low wavenumber region at $(495,303)$ and $(481,305) \mathrm{cm}^{-1}$, respectively, can be attributed to weak metaloxygen bonds.

\section{Thermal Analysis}

Thermogravimetric analysis of both complexes reveals the loss of water molecules upon heating. The combined TGA-DSC curves of $\mathbf{1}$ are presented in Figure S3. The compound began to lose coordinated water molecules slowly at $110^{\circ} \mathrm{C}$ and ended at $200^{\circ} \mathrm{C}$ (observed weight loss $18.1 \%$; theoretical weight loss $18.5 \%)$. The slow decomposition supports the involvement of water molecules in $\mathrm{H}$-bonding. The presence of an endothermic peak at $140^{\circ} \mathrm{C}$, indicates the absence of water of crystallization in agreement with the observed formula. After release of water, there is no weight loss up to $320^{\circ} \mathrm{C}$, which indicates a thermally metastable product of empirical formula $\left[\mathrm{Eu}\left(\mathrm{C}_{5} \mathrm{H}_{6} \mathrm{O}_{4}\right)\right]^{+} \mathrm{Cl}^{-}$. Above $320^{\circ} \mathrm{C}$, a continuous decomposition occurs slowly until $1,000^{\circ} \mathrm{C}$ releasing glutarate and chloride ions. At the end $1 / 2$ $\mathrm{Eu}_{2} \mathrm{O}_{3}$ is left behind as a residue with an overall weight loss of 55\% (theoretical 54.8\%).

The thermal decomposition of $\mathbf{2}$ occurs in three stages as shown in Figure S4. At the first stage, a 7.8\% weight loss occurs in the temperature range of 100 to $180^{\circ} \mathrm{C}$, ascribed to the removal of two water molecules (theoretical 7.9\%) followed by a plateau up to $290^{\circ} \mathrm{C}$. The loss of water is associated with an endothermic transition at about $130^{\circ} \mathrm{C}$. In the next stage, a $17.3 \%$ weight loss occurs between 290 and $450^{\circ} \mathrm{C}$ to leave probably two molecules of $\mathrm{CO}_{2}$ (calculated value 19.3\%). The remaining fragment of one glutarate and the second ligand are released in the following step with a $35 \%$ weight loss in the temperature range of $400-$ $800^{\circ} \mathrm{C}$. Some of the oxygen atoms are used in the formation of terbium oxide. The decomposition is completed at about $800^{\circ} \mathrm{C}$. The overall weight loss of $60 \%$ is in excellent agreement with the theoretical weight loss of $59.9 \%$ to leave behind $1 / 4 \mathrm{~Tb}_{4} \mathrm{O}_{7}$ as a residue, which is in good agreement with that described in the literature (Cui et al., 2005). The TG results show that complex 1 possesses higher thermal stability than 2 .

\section{Crystal Structures}

As depicted in Figure S5, the asymmetric unit of 1 contains a $\mathrm{Eu}(\mathrm{III})$ cation, one completely deprotonated gultarate ligand, four coordinated water molecules and a chloride counter ion. Selected bond lengths and angles concerning the coordination are given in Table 1. The complex is polymeric and a segment of the polymeric structure of $\mathbf{1}$ is shown in Figure 1A. Each $\mathrm{Eu}$ (III) ion is coordinated by nine oxygen atoms (five from three independent glutarate ligands and four from water molecules) to form an $\mathrm{EuO}_{9}$ distorted tri-capped trigonal prismatic polyhedron around $\mathrm{Eu}(\mathrm{III})$ (Figure 1B). A pair of europium(III) ions are joined to each other by carboxylate oxygen (O1) atoms of two different glutarate di-anions. The metal-metal separation $\left[\mathrm{Eu} 1 \cdots \mathrm{Eu} 1^{\mathrm{i}}(\mathrm{i}=1-x, 1-y, 2-z)\right]$ in each pair is $4.1074(3)$ $\AA$. The dinuclear units are extended in the form of infinite [001] one dimensional chains. A polyhedral view of the chains is shown in Figure S6. The glutarate ligands exhibit identical bidentate chelating and chelating-bridging binding modes $\left(\mu_{3}-\right.$ $\left.\kappa^{2} O: \kappa O^{\prime}: \kappa O^{\prime \prime}: \kappa O^{\prime \prime \prime}\right)$. The $\mathrm{C} 5 / \mathrm{O} 3 / \mathrm{O} 4$ carboxyl group adopts a simple chelating bonding mode to a single europium(III) ion (both $\mathrm{C}-\mathrm{O}$ distances are equal). The other carboxylate side $(\mathrm{C} 1 / \mathrm{O} 1 / \mathrm{O} 2)$ of glutarate di-anion chelates to one metal ion and bridges to an adjacent metal ion from $\mathrm{O} 1 \mathrm{C} 1-\mathrm{O} 1$ and $\mathrm{C} 1-\mathrm{O} 2$ bond lengths are unequal). The aliphatic chain of the glutarate is characterized by $\mathrm{C} 1-\mathrm{C} 2-\mathrm{C} 3-\mathrm{C} 4$ and $\mathrm{C} 2-\mathrm{C} 3-\mathrm{C} 4-$ $\mathrm{C} 5$ torsion angles of $-169.2(2)^{\circ}$ and $68.9(3)^{\circ}$, respectively, i.e., a trans-gauche conformation. The $\mathrm{Eu}-\mathrm{O}$ distance ranges from 2.3943(17) to 2.5217(16) $\AA$ and the average value is 2.455 $\AA$. These distances are comparable to those in the reported nine-coordinated $\mathrm{Eu}(\mathrm{III})$-carboxylate complexes (Cui et al., 2005; Manna et al., 2006; Zhang et al., 2007; Hussain et al., 2019).

Extensive hydrogen bonding involving coordinated water molecules and $\mathrm{Cl}^{-}$ions adds stability to the coordination

TABLE 1 | Selected bond lengths ( $(\AA)$ and angles $\left(^{\circ}\right)$ for complex $\mathbf{1}$.

\begin{tabular}{lccc}
\hline Bond & Distance (Å) & Bond & Angle( $^{\circ}$ ) \\
\hline Eu1-O1 & $2.4450(16)$ & O1-Eu1-O3 & $76.53(5)$ \\
Eu1-O1 & $2.4879(16)$ & O1 $1^{\mathrm{ii}-E u 1-O 3^{\mathrm{i}}}$ & $128.88(5)$ \\
Eu1-O2i & $2.5217(16)$ & O1-Eu1-O4i & $72.85(5)$ \\
Eu1-O4 & $2.4494(16)$ & O1-Eu1-O8 & $103.27(6)$ \\
Eu1-O3 & $2.4891(16)$ & O4-Eu1-O3 & $52.70(5)$ \\
Eu1-O5 & $2.4196(17)$ & O5-Eu1-O2 & $73.53(6)$ \\
Eu1-O6 & $2.3943(17)$ & O5-Eu1-O7 & $69.77(6)$ \\
Eu1-O7 & $2.4427(18)$ & O6-Eu1-O5 & $72.75(6)$ \\
Eu1-O8 & $2.4450(17)$ & O6-Eu1-O1 & $149.26(6)$ \\
Eu1-Eu1 & O6 & O6-Eu1-O2 & $74.76(5)$ \\
O1-C1 & $1.1074(3)$ & O6-Eu1-O7 & $136.59(6)$ \\
O2-C1 & $1.253(3)$ & O7-Eu1-O8 & $72.98(6)$ \\
C5-O4 & $1.270(3)$ & O8-Eu1-O3 & $73.18(5)$ \\
C5-O3 & $1.270(3)$ & &
\end{tabular}

Symmetry code: (i) $-x+1,-y+1,-z+1$; (ii) $-x+1,-y+1,-z+2$. 

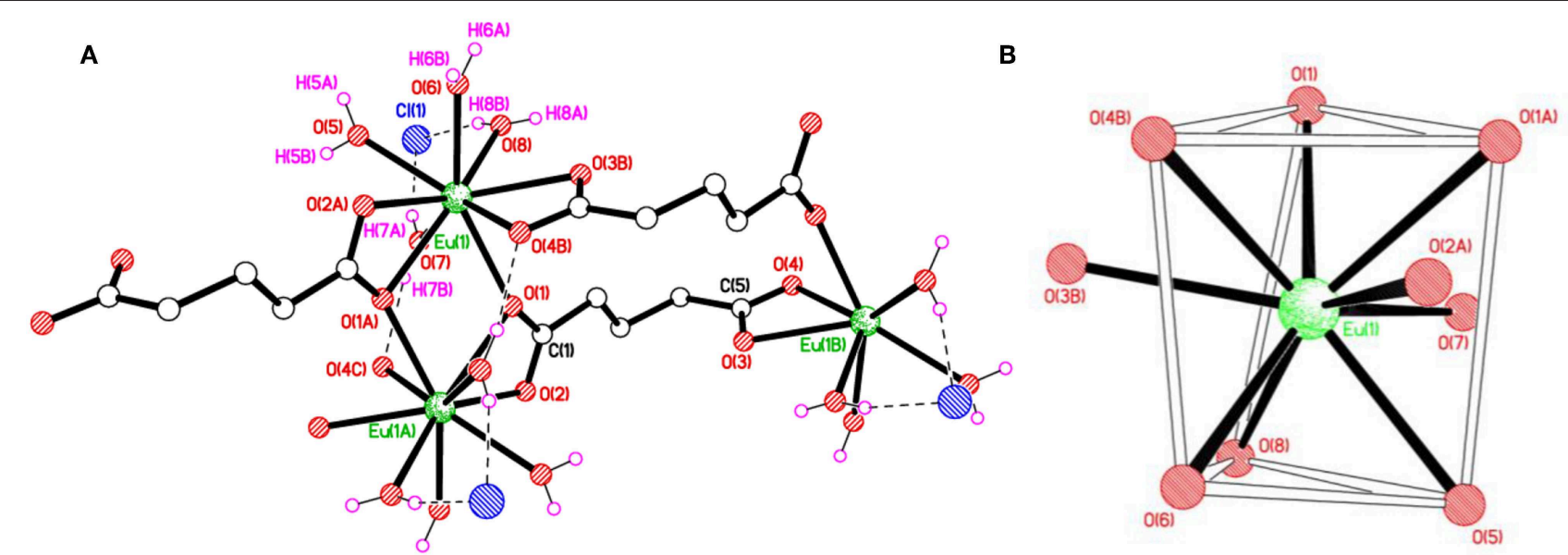

FIGURE 1 | (A) Polymer sub-structure of $\left.\left\{\mathrm{Eu}_{(}\left(\mathrm{C}_{5} \mathrm{H}_{6} \mathrm{O}_{4}\right)\left(\mathrm{H}_{2} \mathrm{O}\right)_{4}\right] \cdot \mathrm{Cl}\right\}_{n}, \mathbf{1}$ with the hydrogen bonds represented by dashed lines. (B) Distorted tri-capped trigonal prismatic coordination environment of $\mathrm{Eu}(1)$ in $\mathbf{1}$.

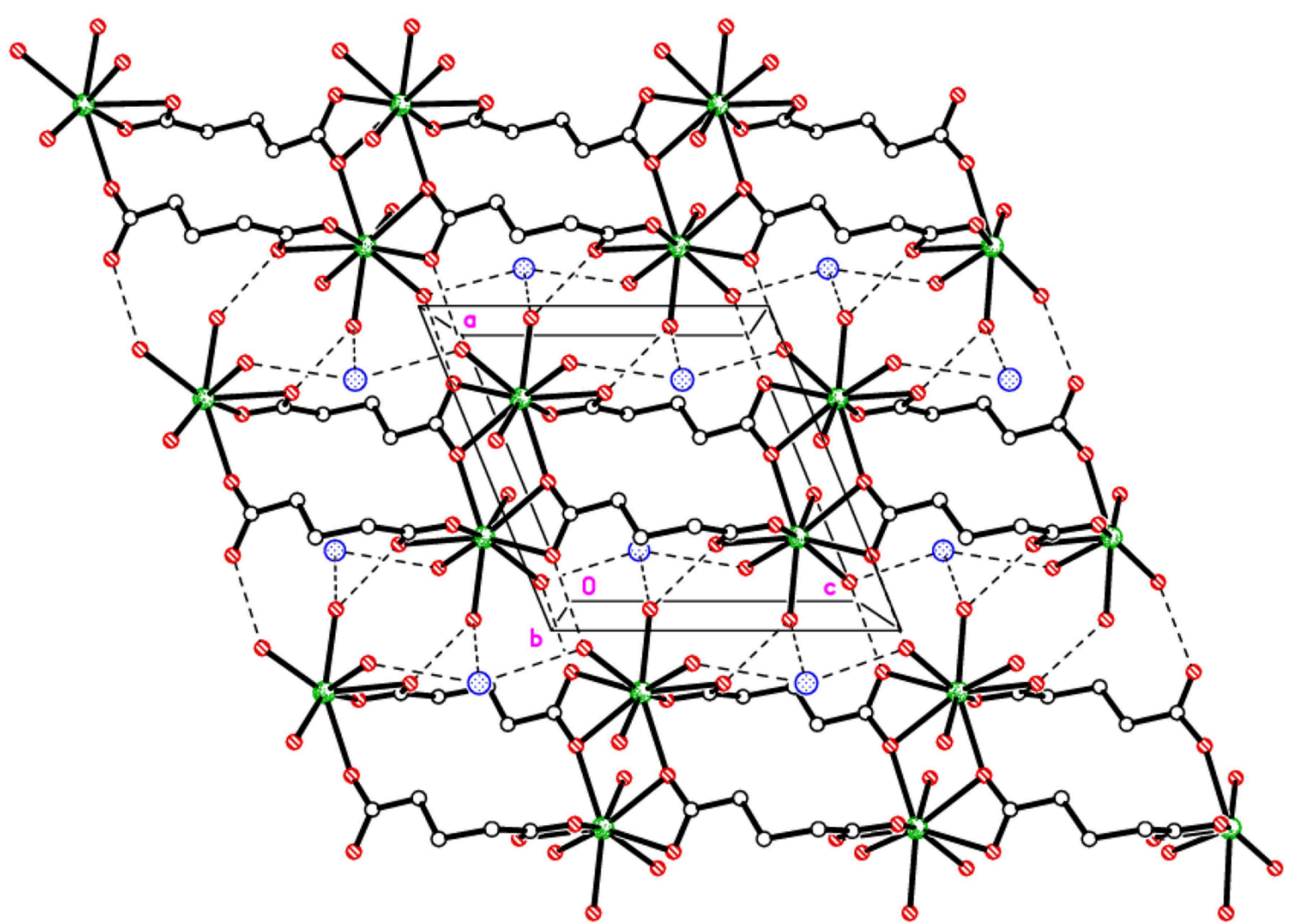

FIGURE 2 | Packing plot of $\left.\left\{\mathrm{Eu}\left(\mathrm{C}_{5} \mathrm{H}_{6} \mathrm{O}_{4}\right)\left(\mathrm{H}_{2} \mathrm{O}\right)_{4}\right] \cdot \mathrm{Cl}\right\}_{n}$, 1 viewed parallel to $b$ showing $1 \mathrm{D}$ covalent ladders linked via $\mathrm{H}$-bonds to form a $2 \mathrm{D}$ sheet.

polymer by connecting three adjacent metal centers as shown in Figure 2. The chloride ion forms hydrogen bonds $(\mathrm{O}-\mathrm{H} \cdots \mathrm{Cl})$ with five water molecules. Moreover, aqua ligands act as donors to the carboxylic $\mathrm{O}$ atoms $\mathrm{O} 2, \mathrm{O} 3$, and $\mathrm{O} 4$ as acceptors $(\mathrm{O}-$ $\mathrm{H}$. . O). The details of hydrogen bonds are provided in Table S2. The hydrogen bonds crosslink the 1D covalent polymeric ladders into a two-dimensional sheet structure. The chloride ions in 1 occupy the regions between the (010) sheets and overall, a $\mathrm{H}$-bonded three-dimensional network arises.

Compound $\mathbf{1}$ is isostructural with our previously reported neodymium analog, $\left\{\left[\mathrm{Nd}\left(\mathrm{C}_{5} \mathrm{H}_{6} \mathrm{O}_{4}\right)\left(\mathrm{H}_{2} \mathrm{O}\right)_{4}\right] \mathrm{Cl}\right\}_{n}$. (Hussain et al., 2015a). In the closely related hydrated compounds 
$\left\{\left[\mathrm{Nd}\left(\mathrm{C}_{5} \mathrm{H}_{6} \mathrm{O}_{4}\right)\left(\mathrm{H}_{2} \mathrm{O}\right)_{4}\right] \mathrm{Cl} \cdot 2 \mathrm{H}_{2} \mathrm{O}\right\}_{n}$ (Legendziewicz et al., 1999) and $\left\{\left[\mathrm{Ce}\left(\mathrm{C}_{5} \mathrm{H}_{6} \mathrm{O}_{4}\right)\left(\mathrm{H}_{2} \mathrm{O}\right)_{4}\right] \mathrm{Cl} \cdot 2 \mathrm{H}_{2} \mathrm{O}\right\}_{n}$ (Rahahlia et al., 2006) similar polymeric chains are formed incorporating both chloride ions and two uncoordinated water molecules per formula unit into the inter-chain voids. However, the coordination mode of glutarate ligands is different in these two compounds. The metal atoms are bound by four glutarate ions. Two of the carboxyl groups exhibit the same chelating bridging mode as observed in 1 (having two contacts to the first metal and one contact to the second metal ion). The other two carboxylates bind with two metal ions as bridging ligands instead of chelating with one metal ion as in $\mathbf{1}$. In case of the analogous succinic acid complexes, $\left\{\left[\mathrm{M}\left(\mathrm{C}_{4} \mathrm{H}_{4} \mathrm{O}_{4}\right)\left(\mathrm{H}_{2} \mathrm{O}\right)_{4}\right] \mathrm{Cl} \cdot 2 \mathrm{H}_{2} \mathrm{O}\right\}_{n}(\mathrm{M}=\mathrm{La}, \mathrm{Ce})$ (Rahahlia et al., 2007), the layer-type polymeric structure is built up from infinite chains of one-edge-sharing $\mathrm{LnO}_{6}\left(\mathrm{H}_{2} \mathrm{O}\right)_{4}$ polyhedra (10-coordinate metal atom) and discrete chloride ions. The metal coordination consists of six oxygen atoms belonging to symmetrically equivalent succinate ligands and four aqua ligands. Only one type of carboxylate binding mode was described; the chelating bridging mode as found for $(\mathrm{C} 1 / \mathrm{O} 1 / \mathrm{O} 2)$ group in 1 . The same bonding pattern of glutarate is found in $\left[\mathrm{Eu}\left(\mathrm{C}_{5} \mathrm{H}_{6} \mathrm{O}_{4}\right)\left(\mathrm{H}_{2} \mathrm{O}\right)_{3}\right] \mathrm{ClO}_{4}$ (Głowiak et al., 1987). The europium ions are nine-coordinate with the coordination sphere made up of six oxygen atoms of glutarate ions and three water molecules.

The structure of $\left[\mathrm{Tb}\left(\mathrm{C}_{5} \mathrm{H}_{7} \mathrm{O}_{4}\right)\left(\mathrm{C}_{5} \mathrm{H}_{6} \mathrm{O}_{4}\right)\left(\mathrm{H}_{2} \mathrm{O}\right)_{2}\right]_{n}, 2$ can be described as chains of dinuclear terbium(III)-(glutarate) (HGlut) units with two terbium ions linked through the $\mathrm{O} 2$ oxygen atoms of bridging glutarate ligands. The C6-monoanions are pendant to the chain (Figure 3A). The $\mathrm{Tb}(1) \cdots \mathrm{Tb}\left(1^{\mathrm{i}}\right)[(\mathrm{i}=1-x$, $-y, 1-z)$ ] distance in centrosymmetric, diamond-shaped $\mathrm{Tb}_{2} \mathrm{O}_{2}$ units is 4.0963(5) $\AA$. The asymmetric unit of 2 comprises of one $\mathrm{Tb}^{3+}$ ion, one mono-protonated glutarate ion (HGlut), one completely deprotonated gultarate dianion, and two coordinated water molecules. The selected bond parameters are listed in
Table 2. Each metal ion in the polymer is coordinated by three bidentate chelating carboxylate groups (two from glutarate dianion and one from HGlut), one bridging carboxylate $\mathrm{O}$ atom and two water molecules. The coordination geometry of $\mathrm{TbO}_{9}$ polyhedron can be described as distorted tri-capped trigonal prismatic (Figure 3B). The bond angles around the metal ions are smaller relative to those in $\mathbf{1}$ leading to a more distorted polyhedron environment for each metal center. A polyhedral view of a [001] chain in 2 showing the edge-sharing $\mathrm{TbO}_{9}$ polyhedra is provided in Figure S7.

TABLE 2 | Selected bond lengths $(\AA \AA)$ and angles $\left(^{\circ}\right)$ for complex 2.

\begin{tabular}{|c|c|c|c|}
\hline Bond & Distance (Å) & Bond & Angles $\left({ }^{\circ}\right)$ \\
\hline $\mathrm{Tb} 1-\mathrm{O} 1$ & $2.448(2)$ & $\mathrm{O} 1-\mathrm{Tb} 1-\mathrm{O} 2$ & $51.23(6)$ \\
\hline $\mathrm{Tb} 1-\mathrm{O} 2$ & $2.582(2)$ & $\mathrm{O} 1-\mathrm{Tb} 1-\mathrm{O}^{\mathrm{ii}}$ & $91.31(7)$ \\
\hline $\mathrm{Tb} 1-\mathrm{O} 2^{\mathrm{i}}$ & 2.3585 (19) & $\mathrm{O} 1-\mathrm{Tb} 1-\mathrm{O} 4^{\mathrm{ii}}$ & $70.73(7)$ \\
\hline $\mathrm{Tb} 1-\mathrm{O}^{\mathrm{ii}}$ & $2.396(2)$ & O1-Tb1-O5 & $145.14(7)$ \\
\hline $\mathrm{Tb} 1-\mathrm{O} 4^{\mathrm{ii}}$ & $2.542(2)$ & $\mathrm{O} 1-\mathrm{Tb} 1-\mathrm{O} 6$ & $145.40(7)$ \\
\hline Tb1-O5 & 2.4706 (19) & O1-Tb1-O9 & $80.89(7)$ \\
\hline $\mathrm{Tb} 1-\mathrm{O} 6$ & $2.443(2)$ & $\mathrm{O} 1-\mathrm{Tb} 1-\mathrm{O} 10$ & $77.57(7)$ \\
\hline Tb1-O9 & $2.334(2)$ & $\mathrm{O} 2-\mathrm{Tb} 1-\mathrm{O}^{\mathrm{i}}$ & $68.04(6)$ \\
\hline Tb1-O10 & $2.345(2)$ & $\mathrm{O} 2-\mathrm{Tb} 1-\mathrm{O} 3^{\mathrm{ii}}$ & $74.95(7)$ \\
\hline $\mathrm{C} 1-\mathrm{O} 1$ & $1.256(3)$ & $\mathrm{O} 2-\mathrm{Tb} 1-\mathrm{O} 4^{\mathrm{ii}}$ & $98.49(6)$ \\
\hline $\mathrm{C} 1-\mathrm{O} 2$ & $1.273(3)$ & $\mathrm{O} 5-\mathrm{Tb} 1-\mathrm{O} 6$ & $52.86(7)$ \\
\hline $\mathrm{C} 5-\mathrm{O} 4$ & $1.264(3)$ & O5-Tb1-O9 & $71.87(7)$ \\
\hline $\mathrm{C} 5-\mathrm{O} 3$ & 1.270 (3) & $\mathrm{O} 5-\mathrm{Tb} 1-\mathrm{O} 10$ & $76.94(7)$ \\
\hline $\mathrm{C} 6-\mathrm{O} 5$ & $1.269(3)$ & $\mathrm{O} 6-\mathrm{Tb} 1-\mathrm{O} 3^{\mathrm{ii}}$ & $76.62(7)$ \\
\hline $\mathrm{C} 6-\mathrm{O} 6$ & $1.266(3)$ & & \\
\hline
\end{tabular}

Symmetry codes: (i) $-x+1,-y,-z+1$ (ii) $-x+1,-y,-z+2$.
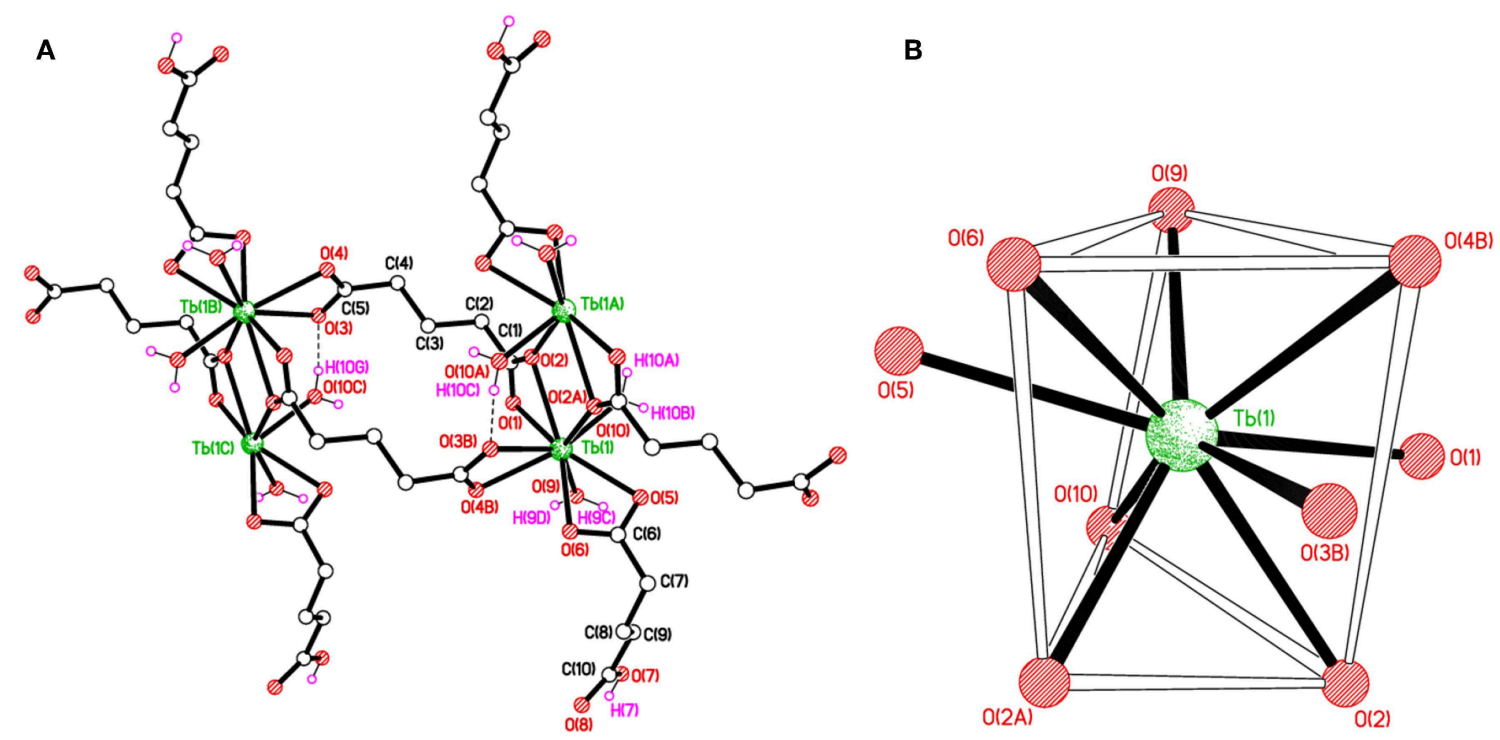

FIGURE 3 | (A) Polymer sub-structure of $\left[\mathrm{Tb}\left(\mathrm{C}_{5} \mathrm{H}_{7} \mathrm{O}_{4}\right)\left(\mathrm{C}_{5} \mathrm{H}_{6} \mathrm{O}_{4}\right)\left(\mathrm{H}_{2} \mathrm{O}\right)_{2}\right]_{n}$, 2. (B) Distorted tri-capped trigonal prismatic coordination environment of $\mathrm{Tb}(1)$ in 2. 
The glutarate di-anion coordinates in the same way as found in 1. The C1-containing carboxyl group chelates to a metal ion from the $\mathrm{C} 1 / \mathrm{O} 1 / \mathrm{O} 2$ moiety and one of the chelating $\mathrm{O}$ atoms $\mathrm{O}(2)$ bridges an adjacent metal atom. The $\mathrm{C}(5) / \mathrm{O}(3) / \mathrm{O}(4)$ moiety follows a chelating bonding mode to $\mathrm{Tb} 1$, the next metal along the chain. The carbon-atom chain of the $\mathrm{C}(1)$ anion adopts an extended conformation [C1-C2-C3-C4 = 173.4(2) ${ }^{\circ}$; C2-C3$\left.\mathrm{C} 4-\mathrm{C} 5=179.4(2)^{\circ}\right]$. The mono-anion glutarate chelates to $\mathrm{Tb} 1$ through $\mathrm{C6} / \mathrm{O} 5 / \mathrm{O} 6$ and the other end is protonated carboxylic group $\mathrm{C} 10 / \mathrm{O} 7 / \mathrm{O} 8$ does not participate in coordination. The backbone carbon chains have unique gauche $\mathrm{C} 6-\mathrm{C} 7-\mathrm{C} 8-\mathrm{C} 9$ $\left[74.0(3)^{\circ}\right]$ and anti. C7-C8-C9-C10 $\left[-176.9(3)^{\circ}\right]$ conformation. The mean $\mathrm{Tb}-\mathrm{O}$ distance $2.434 \AA$ is in accordance with the reported literature (Cui et al., 2005; Qiongyan et al., 2008; Hussain et al., 2019). The coordination bond lengths in $\mathbf{2}$ are slightly shorter, in comparison with $\mathbf{1}$, which is in accordance with the slightly smaller ionic radius of $\mathrm{Tb}^{3+}$ (Hussain et al., 2019).

The structure of $\mathbf{2}$ is supported by $\mathrm{O}-\mathrm{H}$. . O hydrogen bonds including carboxylates and water molecules and details are given in Table S3. The carboxylate O7 hydrogen bonds crosslink the 1D polymeric chains into a two-dimensional layer as shown in Figure 4A. The layers are further connected to build a threedimensional network (Figure 4B).

\section{Luminescent Properties}

The solid state photoluminescence properties of $\mathbf{1}$ and $\mathbf{2}$ were investigated at room temperature.

The excitation spectrum of $\mathbf{1}$ was measured to monitor the ${ }^{5} \mathrm{D}_{0} \rightarrow{ }^{7} \mathrm{~F}_{2}$ transitions of europium at $616 \mathrm{~nm}$ as shown in Figure 5A. The major excitation peaks of europium are observed at $286 \mathrm{~nm}\left({ }^{7} \mathrm{~F}_{0} \rightarrow{ }^{5} \mathrm{I}_{8}\right), 298 \mathrm{~nm}\left({ }^{7} \mathrm{~F}_{0} \rightarrow{ }^{5} \mathrm{~F}_{2}\right), 318 \mathrm{~nm}\left({ }^{7} \mathrm{~F}_{0} \rightarrow\right.$ $\left.{ }^{5} \mathrm{H}_{3}\right), 362 \mathrm{~nm}, 367 \mathrm{~nm}\left({ }^{7} \mathrm{~F}_{0,1} \rightarrow{ }^{5} \mathrm{D}_{4}\right), 375 \mathrm{~nm}, 381 \mathrm{~nm}, 385 \mathrm{~nm}$ $\left({ }^{7} \mathrm{~F}_{0} \rightarrow{ }^{5} \mathrm{~L}_{7,8,9}\right), 395 \mathrm{~nm}\left({ }^{7} \mathrm{~F}_{0} \rightarrow{ }^{5} \mathrm{~L}_{6}\right)$ and $417 \mathrm{~nm}\left({ }^{7} \mathrm{~F}_{0} \rightarrow\right.$ $\left.{ }^{5} \mathrm{D}_{3}\right)$. All the excitation peaks in $\mathbf{1}$ arise from ground level ${ }^{7} \mathrm{~F}_{0}$ except ${ }^{5} \mathrm{D}_{4}$ which arises from level ${ }^{7} \mathrm{~F}_{1}$. The most intense among them is ${ }^{7} \mathrm{~F}_{0} \rightarrow{ }^{5} \mathrm{~L}_{6}$. These excitation peaks have been observed in previously reported europium compounds (Baur et al., 2015; Marques et al., 2015). A very weak signal appeared at $268 \mathrm{~nm}$ due to transition of the ligand expected to produce luminescence emission. The other ligand transitions are superimposed on the strong ${ }^{7} \mathrm{~F}_{0} \rightarrow{ }^{5} \mathrm{I}_{8}$ and ${ }^{7} \mathrm{~F}_{0} \rightarrow{ }^{5} \mathrm{~F}_{2}$ transition of europium. The emission spectrum of $\mathbf{1}$ was recorded under the excitation wavelength of $268 \mathrm{~nm}$ and is shown in Figure 5B. It exhibits four characteristic peaks in the visible region at 598,616,656, and $699 \mathrm{~nm}$, which belong to the ${ }^{5} \mathrm{D}_{0} \rightarrow{ }^{7} \mathrm{~F}_{1},{ }^{5} \mathrm{D}_{0} \rightarrow{ }^{7} \mathrm{~F}_{2},{ }^{5} \mathrm{D}_{0}$ $\rightarrow{ }^{7} \mathrm{~F}_{3}$, and ${ }^{5} \mathrm{D}_{0} \rightarrow{ }^{7} \mathrm{~F}_{4}$ transitions of the europium(III) ion, respectively. The most intense was the induced electric dipole transition ${ }^{5} \mathrm{D}_{0} \rightarrow{ }^{7} \mathrm{~F}_{2}$ which is highly sensitive for the chemical bond in the environs of a europium(III) ion, and responsible for the red emission when irradiated under UV light (Cui et al., 2005; Gu and Xue, 2006; Hou et al., 2014).

Whereas ${ }^{5} \mathrm{D}_{0} \rightarrow{ }^{7} \mathrm{~F}_{1}$ is the magnetic dipole transition, which is rather less sensitive to the coordinated environment and is relatively weak when compared with the electric dipole transition $\left({ }^{5} \mathrm{D}_{0} \rightarrow{ }^{7} \mathrm{~F}_{2}\right)$. The $\mathrm{Eu}(\mathrm{III})$ transition rule states that when the center of inversion exists on europium(III), the magnetic dipole transition $\left({ }^{5} \mathrm{D}_{0} \rightarrow{ }^{7} \mathrm{~F}_{1}\right)$ will be more intense emitting orange light instead of red light, emitting electric dipole transition $\left({ }^{5} \mathrm{D}_{0} \rightarrow{ }^{7} \mathrm{~F}_{2}\right)$ (Hou et al., 2014). The crystal field strength acting on europium(III) also affects the intensity of the magnetic dipole transition ( $\mathrm{Gu}$ and Xue, 2006). As the site

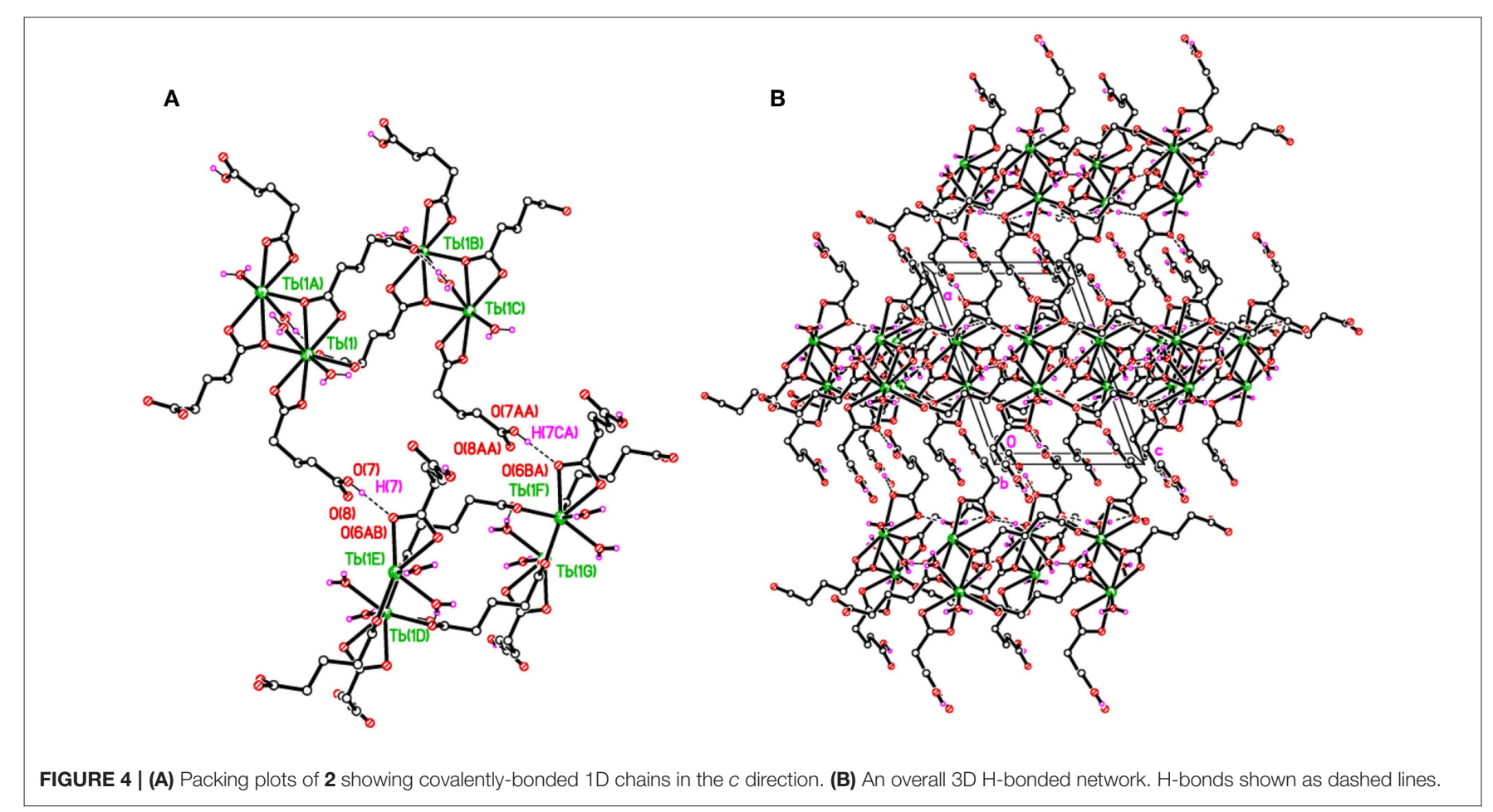



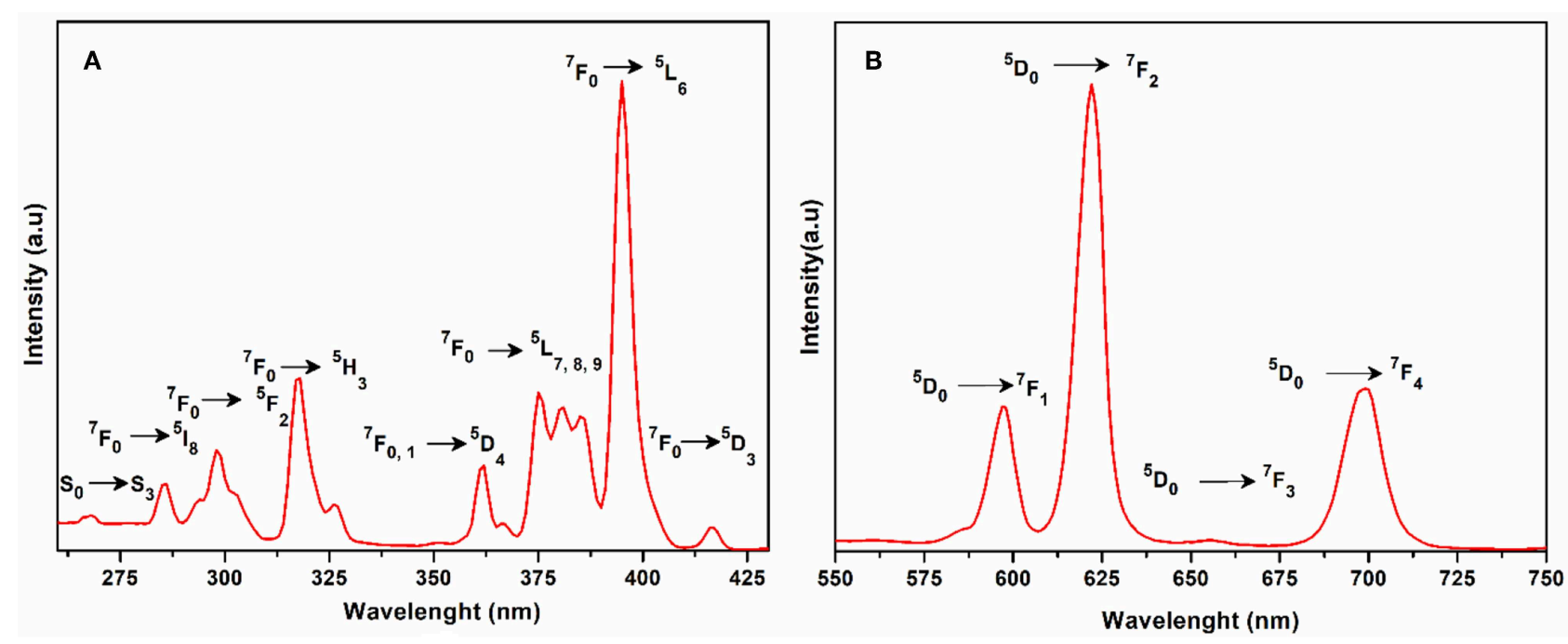

FIGURE 5 | (A) Solid state excitation spectrum of $\mathbf{1}$ to monitor emission at $616 \mathrm{~nm}$. (B) Solid state emission spectrum of $\mathbf{1}$ excited at $268 \mathrm{~nm}$.

symmetry of the $\mathrm{Eu}(\mathrm{III})$ ion decreases, the intensity of the electric dipole transition ${ }^{5} \mathrm{D}_{0} \rightarrow{ }^{7} \mathrm{~F}_{2}$ increases. By comparing the intensity ratio of ${ }^{5} \mathrm{D}_{0} \rightarrow{ }^{7} \mathrm{~F}_{1}(598 \mathrm{~nm})$ and ${ }^{5} \mathrm{D}_{0} \rightarrow{ }^{7} \mathrm{~F}_{2}$ $(616 \mathrm{~nm})$ for 1 , the peak intensity ratio is about $1: 3$ which suggests that the coordination of the europium ions does not have an inversion center on the local site and exists in a low symmetry environment as is evident by the structural analysis of compound 1 (Hou et al., 2014).

The excitation spectrum of 2 (Figure 6A) was measured to observe the ${ }^{5} \mathrm{D}_{4} \rightarrow{ }^{7} \mathrm{~F}_{\mathrm{n}}$ transitions of terbium at $545 \mathrm{~nm}$. The excitation spectrum exhibited the following transitions of terbium; ${ }^{7} \mathrm{~F}_{6} \rightarrow{ }^{5} \mathrm{H}_{3}(266 \mathrm{~nm}) ;{ }^{7} \mathrm{~F}_{6} \rightarrow{ }^{5} \mathrm{H}_{4}(273 \mathrm{~nm}) ;{ }^{7} \mathrm{~F}_{6} \rightarrow$ ${ }^{5} \mathrm{I}_{8}(286 \mathrm{~nm}) ;{ }^{7} \mathrm{~F}_{6} \rightarrow{ }^{5} \mathrm{H}_{5}(296 \mathrm{~nm}) ;{ }^{7} \mathrm{~F}_{6} \rightarrow{ }^{5} \mathrm{H}_{6}(304 \mathrm{~nm}) ;{ }^{7} \mathrm{~F}_{6}$ $\rightarrow{ }^{5} \mathrm{H}_{7}(319 \mathrm{~nm}) ;{ }^{7} \mathrm{~F}_{6} \rightarrow{ }^{5} \mathrm{D}_{1}(327 \mathrm{~nm}) ;{ }^{7} \mathrm{~F}_{6} \rightarrow{ }^{5} \mathrm{H}_{7,8},{ }^{5} \mathrm{G}_{3}$ $(342 \mathrm{~nm}) ;{ }^{7} \mathrm{~F}_{6} \rightarrow{ }^{5} \mathrm{~L}_{9},{ }^{5} \mathrm{G}_{5}(351 \mathrm{~nm}) ;{ }^{7} \mathrm{~F}_{6} \rightarrow{ }^{5} \mathrm{D}_{2}(360 \mathrm{~nm}) ;$ ${ }^{7} \mathrm{~F}_{6} \rightarrow{ }^{5} \mathrm{~L}_{10}(370 \mathrm{~nm})$; and ${ }^{7} \mathrm{~F}_{6} \rightarrow{ }^{5} \mathrm{G}_{5},{ }^{5} \mathrm{D}_{3}(380 \mathrm{~nm})$. All these transitions originate from the ${ }^{7} \mathrm{~F}_{6}$ ground state and the strongest of these are: ${ }^{7} \mathrm{~F}_{6} \rightarrow{ }^{5} \mathrm{~L}_{9},{ }^{5} \mathrm{G}_{5}$ and ${ }^{7} \mathrm{~F}_{6} \rightarrow{ }^{5} \mathrm{~L}_{10}$. The weak ligand transitions are superimposed on the ${ }^{7} \mathrm{~F}_{6} \rightarrow$ ${ }^{5} \mathrm{H}_{3}(266 \mathrm{~nm}),{ }^{7} \mathrm{~F}_{6} \rightarrow{ }^{5} \mathrm{H}_{4}(273 \mathrm{~nm}),{ }^{7} \mathrm{~F}_{6} \rightarrow{ }^{5} \mathrm{I}_{8}(286 \mathrm{~nm})$, and ${ }^{7} \mathrm{~F}_{6} \rightarrow{ }^{5} \mathrm{H}_{5}(296 \mathrm{~nm})$ transition of the terbium, which are more dominant in the excitation spectra. The excitation pattern of 2 closely matches with the previously reported powder MOF of terbium-thenoyltriflouroacetone (Medina-Velazquez et al., 2019). As shown in Figure 6B under the excitation wavelength of $268 \mathrm{~nm}$, the emission spectrum of 2 exhibits four intense characteristic transitions of terbium at $494 \mathrm{~nm}\left({ }^{5} \mathrm{D}_{4} \rightarrow{ }^{7} \mathrm{~F}_{6}\right)$, $545 \mathrm{~nm}\left({ }^{5} \mathrm{D}_{4} \rightarrow{ }^{7} \mathrm{~F}_{5}\right), 588 \mathrm{~nm}\left({ }^{5} \mathrm{D}_{4} \rightarrow{ }^{7} \mathrm{~F}_{4}\right)$, and $625 \mathrm{~nm}\left({ }^{5} \mathrm{D}_{4}\right.$ $\rightarrow{ }^{7} \mathrm{~F}_{3}$ ). In spite of this, there are also three weak peaks at 652 , 672 , and $683 \mathrm{~nm}$ attributed to the ${ }^{5} \mathrm{D}_{4} \rightarrow{ }^{7} \mathrm{~F}_{2},{ }^{5} \mathrm{D}_{4} \rightarrow{ }^{7} \mathrm{~F}_{1}$, and ${ }^{5} \mathrm{D}_{4} \rightarrow{ }^{7} \mathrm{~F}_{0}$ emissions, respectively. An induced electric dipole transition $\left({ }^{5} \mathrm{D}_{4} \rightarrow{ }^{7} \mathrm{~F}_{5}\right)$ that is sensitive to the coordination environment of the terbium exhibits the strongest emission at $545 \mathrm{~nm}$, which is characterized by the green luminescence output when the solid sample is excited under UV light. The magnetic transition $\left({ }^{5} \mathrm{D}_{4} \rightarrow{ }^{7} \mathrm{~F}_{6}\right)$, which is less sensitive to the coordination environment is relatively weak when compared with the electric dipole transition $\left({ }^{5} \mathrm{D}_{4} \rightarrow{ }^{7} \mathrm{~F}_{5}\right)$ with intensity ratio close to $1: 3\left({ }^{5} \mathrm{D}_{4} \rightarrow{ }^{7} \mathrm{~F}_{6}:{ }^{5} \mathrm{D}_{4} \rightarrow{ }^{7} \mathrm{~F}_{5}\right)$ (Bogale et al., 2017a).

The fluorescence emissions of europium and terbium in different compounds have been reported for sensing metal ions (Zhao et al., 2004; Bogale et al., 2016, 2017a), nitro compounds (Bogale et al., 2016, 2017a), and solvent molecules (Li et al., 2013; Wang et al., 2014). The emission behavior of $\mathbf{1}$ and $\mathbf{2}$ were investigated in various solvents, such as methanol, ethanol, THF, DMSO, DMF, water, acetone, and dichloromethane. Complexes $\mathbf{1}$ and $\mathbf{2}$ show good luminescence in these solvents (Figures S8, S9, respectively) except in acetone and dichloromethane in which they exhibit a strong quenching effect on emission intensity. Thus, $\mathbf{1}$ and $\mathbf{2}$ could be used as sensors for acetone and dichloromethane. When $\mathbf{1}$ and $\mathbf{2}$ were suspended in methanol they exhibited strong emission peaks as compared with other solvents. The fluorescence life time calculated for compounds $\mathbf{1}$ and 2 are 2.499 ns and 2.895 ns, respectively.

\section{Detection of Metals Ions}

In order to investigate the sensing properties of complexes 1 and 2 toward various metals ions, such as $\mathrm{Na}^{+}, \mathrm{Mg}^{2+}$, $\mathrm{Al}^{3+}, \mathrm{Cr}^{3+}, \mathrm{Mn}^{2+}, \mathrm{Fe}^{2+}, \mathrm{Fe}^{3+}, \mathrm{Co}^{2+}, \mathrm{Ni}^{2+}, \mathrm{Zn}^{2+}$ and $\mathrm{Cd}^{2+}$, aqueous solutions of chloride salts of these metals were added individually to solutions of $\mathbf{1}$ and $\mathbf{2}$ dispersed in methanol under the same conditions. As shown in Figures $7 \mathbf{A}, \mathbf{B}$, only $\mathrm{Fe}^{3+}$ was able to induce significant fluorescence quenching of $\mathbf{1}$ and $\mathbf{2}$, respectively. As compared with the initial solution (control), the fluorescence intensity of $\mathbf{1}$ and $\mathbf{2}$ were reduced about 83 and $85 \%$, respectively, by the addition of aqueous solution of $\mathrm{Fe}^{3+}$, while the addition of other metals has no appreciable effect on the fluorescence intensity under the same test conditions as shown in Figures S10, S11, respectively. These results suggest that 1 and $\mathbf{2}$ are highly sensitive for the $\mathrm{Fe}^{3+}$ ion and induce distinct 

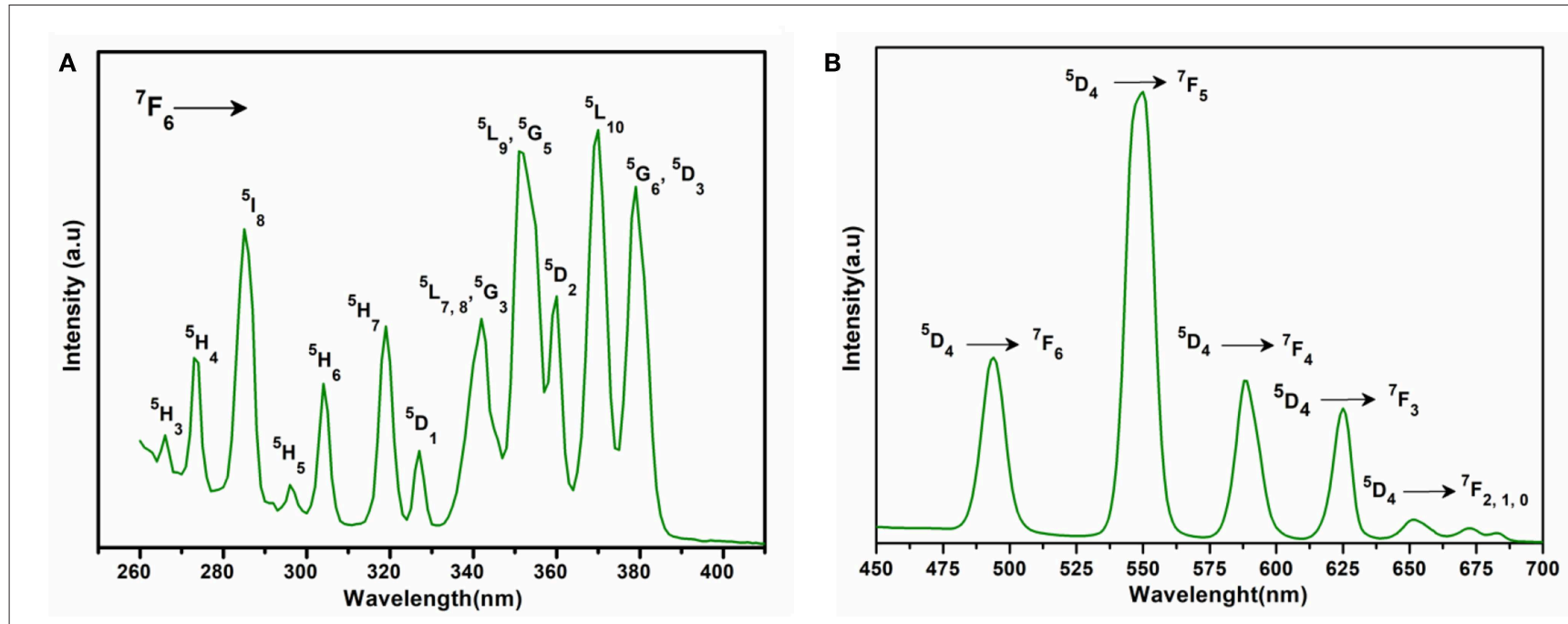

FIGURE 6 | (A) Solid state excitation spectrum of 2 to monitor emission at $545 \mathrm{~nm}$. (B) Solid state emission spectrum of 2 excited at $268 \mathrm{~nm}$.
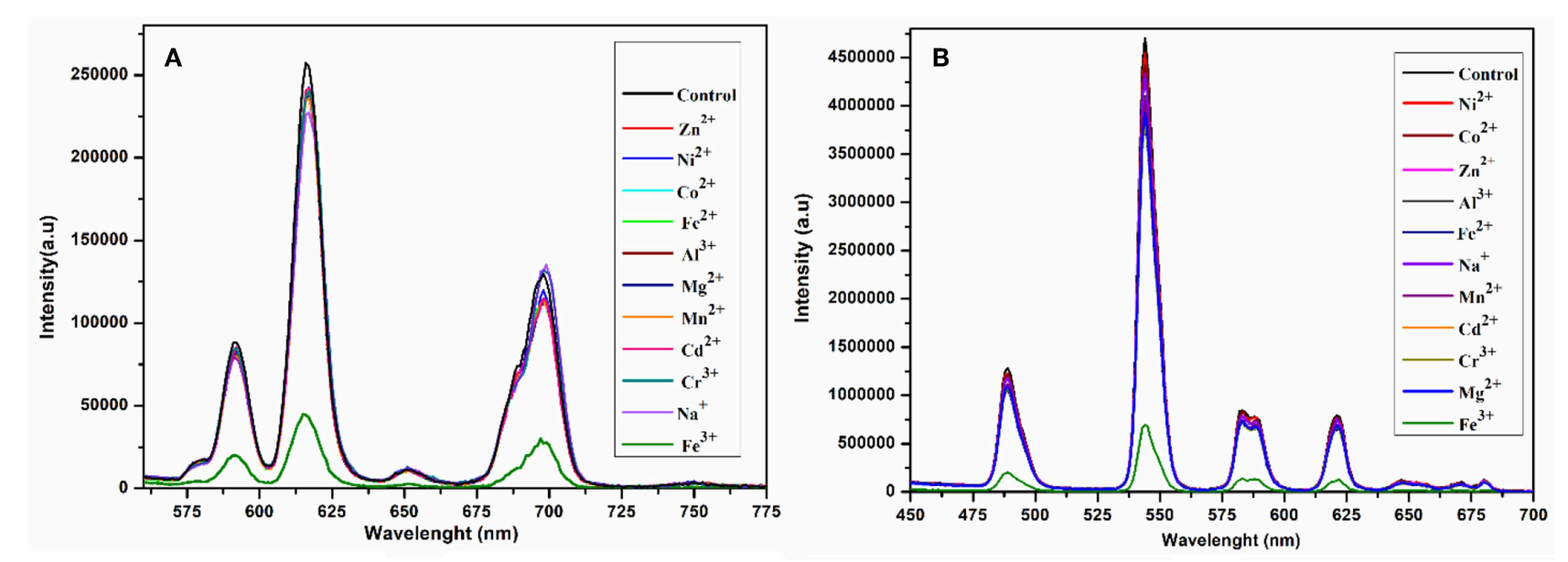

FIGURE 7 | Change in emission spectra of $\mathbf{1}$ at $616 \mathrm{~nm}(\mathbf{A})$ and $\mathbf{2}$ at $545 \mathrm{~nm}$ (B) after interacting with different metal ions in aqueous solution under the same conditions excited at $268 \mathrm{~nm}$.

fluorescence quenching as compared with the other metals ions. Furthermore, the sensitivity tests of $\mathbf{1}$ and $\mathbf{2}$ were carried out by progressive addition of an aqueous solution of $\mathrm{Fe}^{3+}$ ion to the solutions of $\mathbf{1}$ and $\mathbf{2}$ suspended in methanol. The gradual addition of an aqueous solution of $\mathrm{Fe}^{3+}$ to the methanolic solution of $\mathbf{1}$ and 2 produced sequential quenching of fluorescence emission at $616 \mathrm{~nm}$ (Figure 8A) and 545 (Figure 8B) nm, respectively. The Figures S12, S13 depict that the luminescence quenching efficiencies and concentration of $\mathrm{Fe}^{3+}$ are in good agreement with linear proportion with $\mathrm{R}$ values of 0.9949 and 0.9734 for $\mathbf{1}$ and $\mathbf{2}$, respectively. The detection limits for and $\mathbf{1}$ and $\mathbf{2}$, estimated from the linear regression curves, were found to be $4.6565 \times$ $10^{-7} \mathrm{M}$ and $1.612 \times 10^{-7} \mathrm{M}$, respectively, which is comparable with the reported terbium and europium coordination polymers for the detection of $\mathrm{Fe}^{3+}$ (Bogale et al., 2016, 2017a,b; Gao et al., 2016). The Stern-Volmer equation $\frac{I_{0}}{I}=\left(1+K_{s v}[Q]\right)$ was used; where $I_{0}$ and $I$ are luminescence intensity before and after addition of quencher, respectively, $Q$ is the quencher concentration and $K_{s v}$ is the quenching coefficient constant. The value of $K_{s v}$ was found to be $1.31 \times 10^{5} \mathrm{M}^{-1}$ and (for 1) and $8.07 \times 10^{4} \mathrm{M}^{-1}$ (for 2), which suggest that the static and dynamic quenching processes are dominant as revealed by the reported studies (Bogale et al., 2016, 2017a,b; Gao et al., 2016).

The sensitivity and selectivity of compounds $\mathbf{1}$ and $\mathbf{2}$ toward $\mathrm{Fe}^{3+}$ were speculated due to the reason that $\mathrm{Fe}^{3+}$ ions diffused into the pores generated by the one-dimensional layers of $\mathbf{1}$ and $\mathbf{2}$, and interact with the carboxylate oxygen and aqua ligands (Dong et al., 2015). Thus, complexation and incorporation of $\mathrm{Fe}^{3+}$ may reduce the energy transfer from ligand to $\mathrm{Eu}^{3+}$ and $\mathrm{Tb}^{3+}$ in $\mathbf{1}$ and 2, respectively, and produce efficient fluorescence quenching. Another possible reason for luminescence quenching is exchange of $\mathrm{Eu}^{3+}$ and $\mathrm{Tb}^{3+}$ with $\mathrm{Fe}^{3+}$ in $\mathbf{1}$ and $\mathbf{2}$, respectively (Zheng et al., 2013; Bogale et al., 2016). 

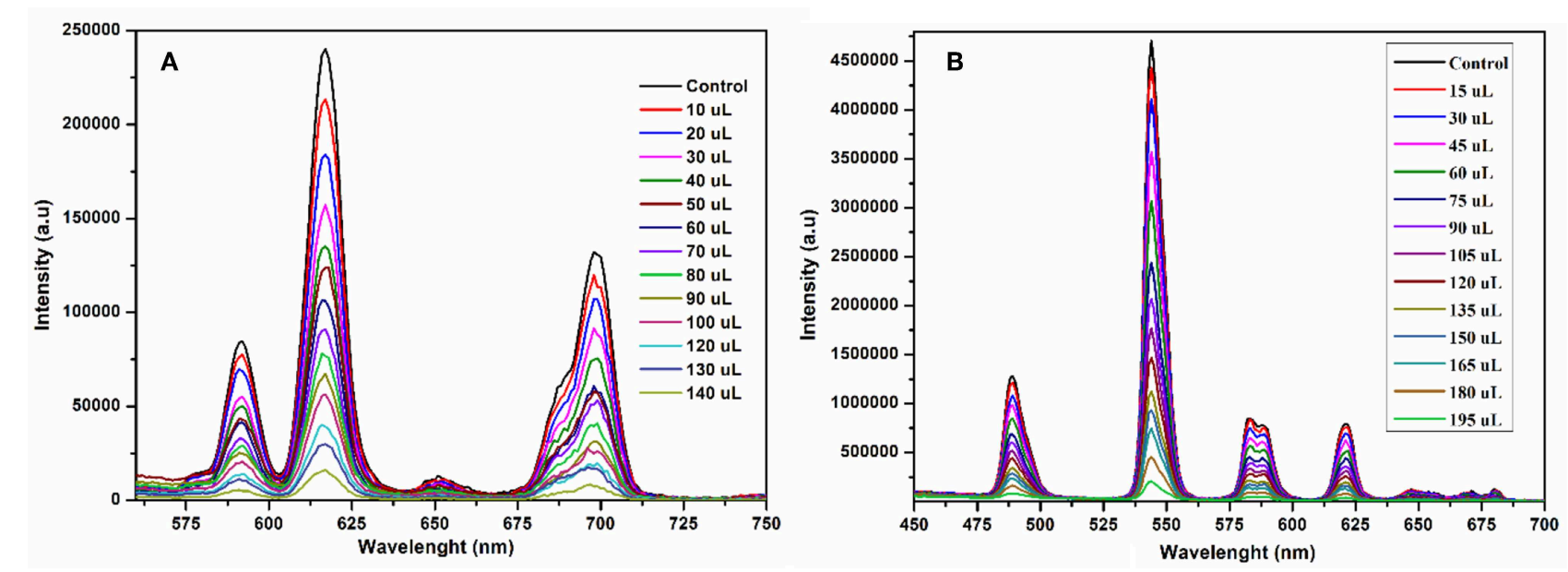

FIGURE 8 | Emission spectra of $\mathbf{1}$ at $616 \mathrm{~nm}$ (A) and $\mathbf{2}$ at $545 \mathrm{~nm}$ (B) suspended in methanol upon incremental addition of Fe ${ }^{3+}$ in aqueous solution under the same conditions excited at $268 \mathrm{~nm}$.

\section{Detection of Aromatics}

To scrutinize the detection capability of $\mathbf{1}$ toward different aromatic and nitroaromatic compounds; bromobenzene (BB), 1,3-dimethylbenzene (DMB), nitrobenzene (NB), 4-nitrotolune (4-NT), 4-nitrophenol (4-NP), 2,6-dinitrophenol (DNP), and 2,4,6-trinitrophenol (TNP) were selected. In doing so, equal volumes of these compounds were added to the methanolic suspension of $\mathbf{1}$ and their luminescence spectra were recorded as shown in Figure 9A. Interestingly, the emission intensity of 1 was highly reduced after addition of 4-nitrophenol, while the other analogous compounds have negligible quenching effect on the emission intensity. The decreasing potential for quenching efficiency is described as: 4-nitrophenol (4-NP) $>$ 2,4,6-trinitrophenol $(\mathrm{TNP})>$ nitrobenzene $(\mathrm{NB})>2,6-$ dinitrophenol $(\mathrm{DNP})>$ bromobenzene $(\mathrm{BB})>4$-nitrotolune (4 NT) > 1,3-dimethylbenzene (DMB), which deviates a little from the electron deficient trend of these compounds. As shown in Figure S14, 4-nitrophenol is the most efficient quencher for 1 with quenching efficiency of $78 \%$ as compared to the other electron deficient nitroaromatics, such as 2,4,6-trinitrophenol (27\%), nitrobenzene (25\%), 2,6-dinitrophenol (21\%). The least quenching effect is with 1,3-dimethylbenzene (8\%).

The compound $\mathbf{2}$ was also suspended in methanol to explore the sensing ability toward the above-mentioned aromatics and nitroaromatic compounds. The emission spectra were recorded after addition of aromatics and nitroaromatics into the methanolic suspension of 2. As shown in Figure 9B, 4-nitrophenol exhibits significant fluorescence quenching as compared to the other tested compounds. The decreasing order of reducing emission intensity of $\mathbf{2}$ is 4-nitrophenol (4-NP) > 2,6-dinitrophenol (DNP) > 2,4,6-trinitrophenol $(\mathrm{TNP})>$ nitrobenzene $(\mathrm{NB})>4$-nitrotolune $(4-\mathrm{NT})>1,3-$ dimethylbenzene $(\mathrm{DMB})>$ bromobenzene $(\mathrm{BB})$. This trend varies from the electron deficient trend of these compounds. The maximum quenching efficiency for 4-nitrophenol (4NP) was found to be $67.22 \%$ and the least quenching is bromobenzene, found to be $3.37 \%$, while 2,4,6-trinitrophenol and 2,6-dinitrophenol have quenching efficiencies 14.01 and 17.44\%, respectively, as shown in Figure S15.

The fluorescence quenching titrations were performed by successive addition of 4-nitrophenol into $\mathbf{1}$ and $\mathbf{2}$ suspended in methanol. The gradual addition of 4-nitrophenol produced significant fluorescence quenching at $616 \mathrm{~nm}$ (for 1, Figure 10A) and $545 \mathrm{~nm}$ (for 2, Figure 10B). The Figures S16, S17 depict that the luminescence quenching efficiencies and concentration of 4nitrophenol are in good agreement with linear proportion with $R^{2}$ values of 0.9890 and 0.9888 for 1 and 2, respectively. The detection limits for $\mathbf{1}$ and $\mathbf{2}$ from the linear regression curves were found to be $5.0589 \times 10^{-8} \mathrm{M}$ and $6.9173 \times 10^{-8} \mathrm{M}$, respectively, which are comparable with the reported europium and terbium coordination polymers for the detection of 4-nitrophenol (Bogale et al., 2016, 2017a,b; Gao et al., 2016). The calculated Ksv values are $9.4792 \times 10^{4} \mathrm{M}^{-1}$ (for $\mathbf{1}$ ) and $4.5295 \times 10^{4} \mathrm{M}^{-1}$ (for 2), which suggest that the static and dynamic quenching processes are dominant as revealed by the previous studies (Bogale et al., 2016, 2017a,b; Gao et al., 2016).

Therefore, it is surmised that the fluorescence quenching observed in $\mathbf{1}$ and $\mathbf{2}$ by the addition of 4-nitrophenol is due to electronic interaction between 4-nitrophenol and the moieties of 1 and 2 , respectively. The other possible reasons for luminescence quenching are the inner filter effect of 4-nitrophenol and competition between absorption energy of 4-nitrophenol and excitation energy of $\mathbf{1}$ and $\mathbf{2}$ (Bogale et al., 2017b). The excitation energy absorbed by the ligands is further absorbed by the 4nitrophenol, which is responsible for fluorescence quenching (Bogale et al., 2016).

\section{CONCLUSIONS}

In summary, two luminescent europium(III)- and terbium(III)glutarate coordination polymers; $\left.\left[\mathrm{Eu}\left(\mathrm{C}_{5} \mathrm{H}_{6} \mathrm{O}_{4}\right)\left(\mathrm{H}_{2} \mathrm{O}\right)_{4}\right] \mathrm{Cl}\right\}_{\mathrm{n}}(\mathbf{1})$ and $\left[\mathrm{Tb}\left(\mathrm{C}_{5} \mathrm{H}_{7} \mathrm{O}_{4}\right)\left(\mathrm{C}_{5} \mathrm{H}_{6} \mathrm{O}_{4}\right)\left(\mathrm{H}_{2} \mathrm{O}\right)_{2}\right]_{n}$ (2) were synthesized and 

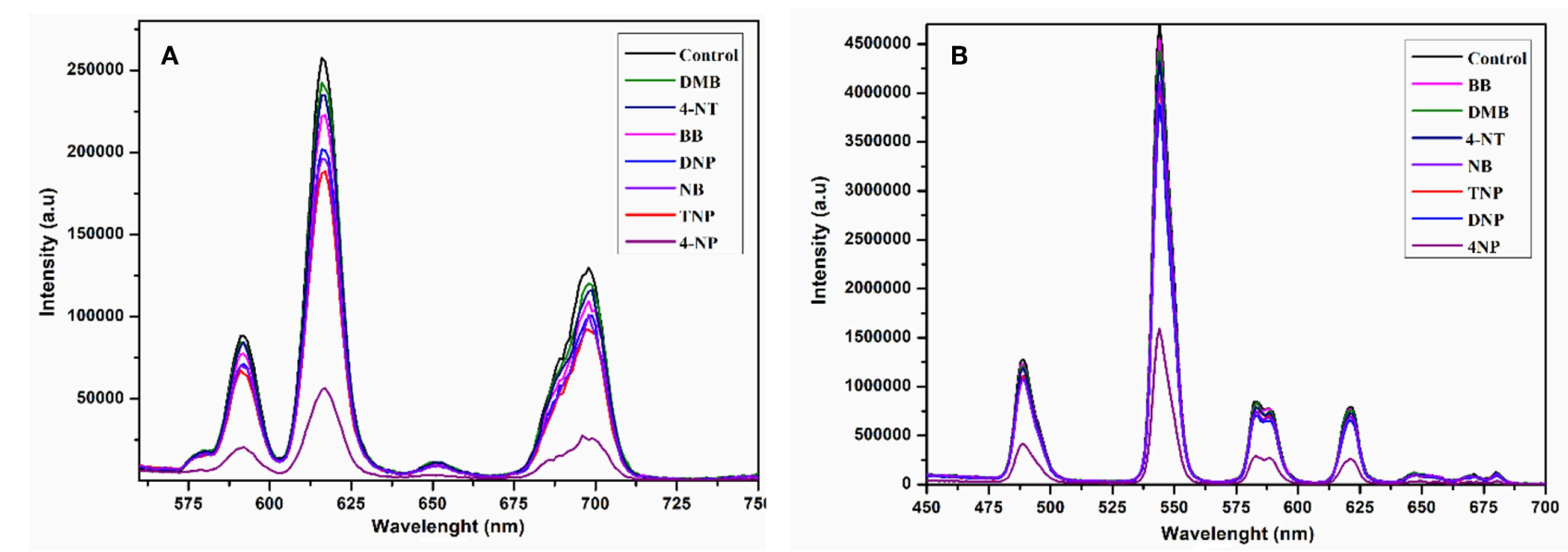

FIGURE 9 | Change in emission spectra of $\mathbf{1}$ at $616 \mathrm{~nm} \mathbf{( A )}$ and $\mathbf{2}$ at $545 \mathrm{~nm}$ (B) after interacting with different aromatics and nitro-aromatics in ethanol under the same conditions excited at $268 \mathrm{~nm}$.
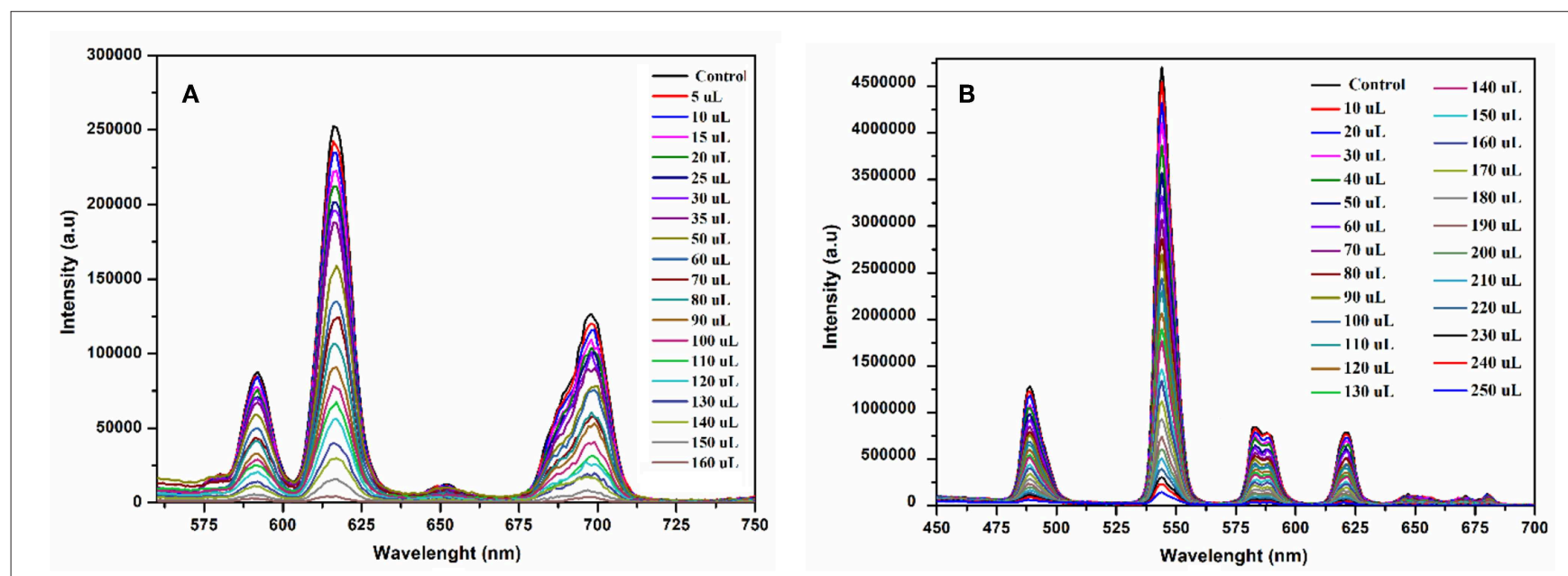

FIGURE 10 | Emission spectra of $\mathbf{1}$ at $616 \mathrm{~nm}$ (A) and 2 at $545 \mathrm{~nm}$ (B) suspended in methanol upon progressive addition 4-nitrophenol ethanolic solution under the same conditions excited at $268 \mathrm{~nm}$.

characterized by IR, TGA and X-ray crystallography. The TGA curves show that after the removal of water molecules, compounds $\mathbf{1}$ and $\mathbf{2}$ are stable up to about $300^{\circ} \mathrm{C}$. The photoluminescence spectra of $\mathbf{1}$ and $\mathbf{2}$ depict the characteristic peaks of europium(III) and terbium(III) ions responsible for the intense red and green emissions, respectively, when irradiated under UV light. The appearance of emission bands in the visible region in the luminescent spectra may recommend their use as long-lived luminescent probes in immuno-assays. The compounds also exhibited good luminescence in various solvents except dichloromethane and acetone. Both complexes exhibit a strong quenching effect on emission intensity when brought into contact with $\mathrm{Fe}^{3+}$ ions and 4-nitrophenol as compared with the other metal ions and nitroaromatics. Furthermore, fluorescence quenching titrations were performed to investigate the sensitivity of complexes for $\mathrm{Fe}^{3+}$ and 4-nitrophenol. By using quenching titration results, the Stern-Volmer graphs were plotted, which suggested that in all cases both static and dynamic quenching processes are dominant. The $K_{s v}$ values of 1 found for $\mathrm{Fe}^{3+}$ and 4-nitrophenol are $1.31 \times 10^{5} \mathrm{M}^{-1}$ and $9.4792 \times 10^{4} \mathrm{M}^{-1}$, respectively. Likewise, for 2 these values for $\mathrm{Fe}^{3+}$ and 4-nitrophenol are $8.07 \times 10^{4} \mathrm{M}^{-1}$ and $4.5295 \times 10^{4} \mathrm{M}^{-1}$ respectively. These results suggest that $\mathbf{1}$ and $\mathbf{2}$ can be applied as promising sensors for the detection of $\mathrm{Fe}^{3+}$ and 4-nitrophenol with excellent sensitivity and selectivity.

\section{DATA AVAILABILITY STATEMENT}

The datasets generated for this study are available on request to the corresponding author. CCDC numbers 1919755 and 1919756 
for 1 and 2, respectively, contain the crystal data of this article. These data are available from Cambridge Crystallographic Data Center via: https://www.ccdc.cam.ac.uk/structures/.

\section{AUTHOR CONTRIBUTIONS}

SA and XC conceived the idea and helped in writing and proof outline. SH has a major role in the synthesis and characterization of compounds as well as in manuscript writing. $\mathrm{ME}$ and DA helped in data collection, structure solution, and refinement. WH wrote the crystal structure descriptions. SL and SM performed the photoluminescence related experiments.

\section{REFERENCES}

Allendorf, M., Bauer, C., Bhakta, R., and Houk, R. (2009). Luminescent metalorganic frameworks. Chem. Soc. Rev. 38, 1330-1352. doi: 10.1039/b802352m

Antic-Fidancev, E., Serpaggi, F., and Férey, G. (2002). Optical study of praseodymium dicarboxylate $\left[\mathrm{Pr}\left(\mathrm{H}_{2} \mathrm{O}\right)\right]_{2}\left[\mathrm{O}_{2} \mathrm{C}\left(\mathrm{CH}_{2}\right)_{3} \mathrm{CO}_{2}\right]_{3} .4 \mathrm{H}_{2} \mathrm{O}$. J. Alloys Compd. 340, 88-94. doi: 10.1016/S0925-8388(02)00052-X

Armelao, L., Quici, S., Barigelletti, F., Accorsi, G., Bottaro, G., Cavazzini, M., et al. (2010). Design of luminescent lanthanide complexes: From molecules to highly efficient photo-emitting materials. Coord. Chem. Rev. 254, 487-505. doi: 10.1016/j.ccr.2009.07.025

Azab, H. A., Duerkop, A., Anwar, Z., Hussein, B. H., Rizk, M. A., and Amin, T. (2013). Luminescence recognition of different organophosphorus pesticides by the luminescent Eu(III)-pyridine-2, 6-dicarboxylic acid probe. Anal. Chim. Acta. 759, 81-91.doi: 10.1016/j.aca.2012.10.045

Bangaru, S., Muralidharan, G., and Brahmanandhan, G. M. (2010). Thermoluminescence and optical studies on X-irradiated terbiumdoped potassium bromide crystals. J. Lumin. 130, 618-622. doi: 10.1016/j.jlumin.2009.11.005

Batool, S. S., Ahmad, S., Khan, I. U., and Ejaz, W. T. A. H. (2015). Structural characterization of a new copper(II) complex of 1,10-phenanthroline and benzoate $\left[\mathrm{Cu}(\mathrm{phen})\left(\mathrm{C}_{6} \mathrm{H}_{5} \mathrm{CO}_{2}^{-}\right)_{2}\right]$. J. Struct. Chem. 56, 387-391. doi: $10.1134 / \mathrm{S} 0022476615020286$

Baur, F., Glocker, F., and Jüstel, T. (2015). Photoluminescence and energy transfer rates and efficiencies in $\mathrm{Eu}^{3+}$ activated $\mathrm{Tb}_{2} \mathrm{Mo}_{3} \mathrm{O}_{12}$. J. Mater. Chem. C 3, 2054-2064. doi: 10.1039/C4TC02588A

Benmerad, B., Guehria-Laidoudi, A., Balegroune, F., Birkedal, H., and Chapuis, G. (2000). Polymeric aqua (glutarato)(hydrogen glutarato) lanthanum(III) monohydrate. Acta Crystallogr. Sect. C Cryst. Struct. Commun. 56, 789-792. doi: $10.1107 /$ S010827010000500X

Binnemans, K. (2009). Lanthanide-based luminescent hybrid materials. Chem. Rev. 109, 4283-4374. doi: 10.1021/cr8003983

Bogale, R. F., Chen, Y., Ye, J., Yang, Y., Rauf, A., Duan, L., et al. (2017a). Highly selective and sensitive detection of 4-nitrophenol and Fe3+ ion based on a luminescent layered terbium(III) coordination polymer. Sens. Actuat. B Chem. 245, 171-178. doi: 10.1016/j.snb.2017.01.177

Bogale, R. F., Chen, Y., Ye, J., Zhang, S., Li, Y., Liu, X., et al. (2017b). A terbium (III)-based coordination polymer for selective and sensitive sensing of nitroaromatics and ferric ion: synthesis, crystal structure and photoluminescence properties. N. J. Chem. 41, 12713-12720. doi: $10.1039 / C 7 N J 02492 \mathrm{D}$

Bogale, R. F., Ye, J., Sun, Y., Sun, T., Zhang, S., Rauf, A., et al. (2016). Highly selective and sensitive detection of metal ions and nitroaromatic compounds by an anionic europium(III) coordination polymer. Dalton Trans. 45, 11137-11144. doi: 10.1039/C6DT01636G

Bromant, C., Nika, W., Pantenburg, I., and Meyer, G. (2005). Selten-erdmetall-koordinationspolymere: synthesen und kristallstrukturen von drei neuen Glutaraten, $\left[\operatorname{Pr}_{2}(\mathrm{Glu})_{3}\left(\mathrm{H}_{2} \mathrm{O}\right)_{4}\right] \cdot 5 \mathrm{H}_{2} \mathrm{O},\left[\mathrm{Pr} \quad(\mathrm{Glu})\left(\mathrm{H}_{2} \mathrm{O}\right)_{2}\right] \mathrm{Cl}$

\section{ACKNOWLEDGMENTS}

XC thanks the National Natural Science Foundation of China (Grant Nos. 21771057 and U1804253). SH is grateful to Henan Normal University for a postdoctoral fellowship. The authors also extend their appreciation to Deanship of Scientific Research at King Khalid University under grant number (R.G.P2/17/40).

\section{SUPPLEMENTARY MATERIAL}

The Supplementary Material for this article can be found online at: https://www.frontiersin.org/articles/10.3389/fchem. 2019.00728/full\#supplementary-material

and $\left[\mathrm{Er}(\mathrm{Glu})(\mathrm{GluH})\left(\mathrm{H}_{2} \mathrm{O}\right)_{2}\right]$. Z. Anorg. Allg. Chem. 631, 2416-2422. doi: 10.1002/zaac.200500253

Bünzli, J.-C. G. (2010). Lanthanide luminescence for biomedical analyses and imaging. Chem. Rev.110, 2729-2755. doi: 10.1021/cr900362e

Bünzli, J. C. G. (2015). On the design of highly luminescent lanthanide complexes. Coord. Chem. Rev. 293, 19-47. doi: 10.1016/j.ccr.2014.10.013

Chen, B., Wang, L., Xiao, Y., Fronczek, F. R., Xue, M., Cui, Y., et al. (2009). A luminescent metal-organic framework with lewis basic pyridyl sites for the sensing of metal ions. Angew. Chem. Int. Ed. 48, 500-503. doi: 10.1002/anie.200805101

Cui, G. H., Li, J. R., Zhang, R.-H., and Bu, X.-H. (2005). Hydrothermal synthesis, crystal structures and luminescent properties of two new $\operatorname{Ln}(\mathrm{III})$-succinate $(\mathrm{Ln}=\mathrm{Eu}, \mathrm{Tb})$ complexes exhibiting three dimensional networks. J. Mol. Struct. 740, 187-191. doi: 10.1016/j.molstruc.2005.01.049

Cui, Y., Yue, Y., Qian, G., and Chen, B. (2011). Luminescent functional metalorganic frameworks. Chem. Rev. 112, 1126-1162. doi: 10.1021/cr200101d

Daiguebonne, C., Kerbellec, N., Guillou, O., Bünzli, J.-C., Gumy, F., Catala, L., et al. (2008). Structural and luminescent properties of micro-and nanosized particles of lanthanide terephthalate coordination polymers. Inorg. Chem. 47, 3700-3708. doi: 10.1021/ic702325m

De Oliveira, C. F., Da Silva, F. F., Malvestiti, I., Malta, V. R. D. S., Dutra, J. D. L., Da Costa, N. B Jr., et al. (2013). Synthesis, characterization, luminescent properties and theoretical study of two new coordination polymers containing lanthanide [Ce(III) or Yb(III)] and succinate ions. J. Mol. Struct. 1041, 61-67. doi: 10.1016/j.molstruc.2013.03.001

Deacon, G. B., and Philips, R. J. (1980). Relationship between the carbon-oxygen stretching frequencies of carboxylate complexes and the type of carboxylate coordination. Coord. Chem. Rev. 33, 227-250. doi: 10.1016/S0010-8545(00)80455-5

Dong, X. Y., Wang, R., Wang, J. Z., Zang, S. Q., and Mak, T. C. (2015). Highly selective $\mathrm{Fe} 3^{+}$sensing and proton conduction in a water-stable sulfonate-carboxylate Tb-organic-framework. J. Mater. Chem. A 3, 641-647. doi: 10.1039/C4TA04421E

Feng, J., and Zhang, H. (2013). Hybrid materials based on lanthanide organic complexes. Chem. Soc. Rev. 42, 387-410. doi: 10.1039/C2CS35069F

Gai, Y. L., Jiang, F. L., Chen, L., Bu, Y., Su, K. Z., Al-Thabaiti, S. A., et al. (2013). Photophysical studies of europium coordination polymers based on a tetracarboxylate ligand. Inorg. Chem. 52, 7658-7665. doi: 10.1021/ic40 $0777 \mathrm{c}$

Gao, M. L., Wei, N., and Han, Z. B. (2016). Anionic metal-organic framework for high-efficiency pollutant removal and selective sensing of Fe(III) ions. RSC Adv. 6, 60940-60944. doi: 10.1039/C6RA08500H

Głowiak, T., Legendziewicz, J., Dao, C. N., and Huskowska, E. (1987). Crystal structure and spectroscopy of lanthanide complexes with glutaric acid $\left[\mathrm{Ln}\left(\mathrm{C}_{5} \mathrm{H}_{6} \mathrm{O}_{4}\right)\left(\mathrm{H}_{2} \mathrm{O}\right)_{3}\right] \cdot \mathrm{ClO}_{4}$. J. Less Common Met. 134, 153-168. doi: 10.1016/0022-5088(87)90553-4

$\mathrm{Gu}, \mathrm{X}$., and Xue, D. (2006). Selected controlled synthesis of threedimensional $4 \mathrm{~d}-4 \mathrm{f}$ heterometallic coordination frameworks by lanthanide 
carboxylate subunits and silver centers. Cryst. Growth Des. 6, 2551-2557. doi: $10.1021 / \operatorname{cg} 060485$ o

Heffern, M. C., Matosziuk, L. M., and Meade, T. J. (2013). Lanthanide probes for bioresponsive imaging. Chem. Rev. 114, 4496-4539. doi: 10.1021/cr400477t

Hou, Y. L., Cheng, R. R., Xiong, G., Cui, J. Z., and Zhao, B. (2014). Structures, luminescent and magnetic properties of a series of $(3,6)$-connected lanthanideorganic frameworks. Dalton Trans. 43, 1814-1820. doi: 10.1039/C3DT52305E

Huang, Y. G., Yuan, D. Q., Gong, Y. Q., Jiang, F. L., and Hong, M. C. (2008). Synthesis, structure and luminescent properties of lanthanide-organic frameworks based on pyridine-2, 6-dicarboxylic acid. J. Mol. Struct. 872, 99-104. doi: 10.1016/j.molstruc.2007.02.020

Hussain, S., Chen, X., Harrison, W. T., Ahmad, S., Elsegood, M., and Muhammad, S. (2019). Synthesis, thermal, structural analyses and photoluminescent properties of a new family of malonatecontaining lanthanide(III) coordination polymers. Front. Chem. 7, 260. doi: $10.3389 /$ fchem. 2019.00260

Hussain, S., Khan, I., Harrison, W., and Tahir, M. (2015a). Crystal structures and characterization of two rare-earth-glutarate coordination networks: One-dimensional $\left[\mathrm{Nd}\left(\mathrm{C}_{5} \mathrm{H}_{6} \mathrm{O}_{4}\right)\left(\mathrm{H}_{2} \mathrm{O}\right)_{4}\right] \bullet \mathrm{Cl}$ and three-dimensional $\left[\operatorname{Pr}\left(\mathrm{C}_{5} \mathrm{H}_{6} \mathrm{O}_{4}\right)\left(\mathrm{C}_{5} \mathrm{H}_{7} \mathrm{O}_{4}\right)\left(\mathrm{H}_{2} \mathrm{O}\right)\right] \bullet \mathrm{H}_{2} \mathrm{O}$. J. Struct. Chem. 56, 934-941. doi: $10.1134 / \mathrm{S} 0022476615050169$

Hussain, S., Khan, I., Harrison, W. T., Tahir, M., and Ahmad, S. (2015b). Crystal structures and characterization of two one-dimensional coordination polymers containing $\mathrm{Ln}^{3+}$ ions and anthranilate $\left(\mathrm{C}_{7} \mathrm{H}_{6} \mathrm{NO}_{2}^{-}\right)$anions. J. Struct. Chem. 56, 126-133.doi: 10.1134/S0022476615010187

Hussain, S., Khan, I. U., Akkurt, M., Ahmad, S., and Tahir, M. N. (2014). Synthesis and structural characterization of binuclear ytterbium(III) complexes with 2-amino and 3-amino benzoic acid. Russ. J. Coord. Chem. 40, 686-694. doi: $10.1134 / \mathrm{S} 107032841409005 \mathrm{X}$

Hussain, S., Khan, I. U., Elsegood, M. R., Jabeen, N., Tahir, M. N., Ahmad, S., et al. (2018). Synthesis and structural characterization of dinuclear cerium(III) and erbium(III) complexes of nicotinic acid or 2-aminobenzoic acid. Polyhedron. 151, 452-457.doi: 10.1016/j.poly.2018.05.057

Kumar, M., Kariem, M., Sheikh, H. N., Frontera, A., Seth, S. K., and Jassal, A. K. (2018). A series of 3D lanthanide coordination polymers decorated with a rigid 3,5-pyridinedicarboxylic acid linker: syntheses, structural diversity, DFT study, Hirshfeld surface analysis, luminescence and magnetic properties. Dalton Trans. 47, 12318-12336. doi: 10.1039/C8DT02429D

Legendziewicz, J., Keller, B., Turowska-Tyrk, I., and Wojciechowski, W. (1999). Synthesis, optical and magnetic properties of homo-and heteronuclear systems and glasses containing them. New J. Chem. 23, 1097-1103. doi: $10.1039 / \mathrm{a} 905284 \mathrm{~d}$

Li, Q.-P., and Yan, B. (2012). Luminescent hybrid materials of lanthanide $\beta$-diketonate and mesoporous host through covalent and ionic bonding with anion metathesis. Dalton Trans. 41, 8567-8574. doi: 10.1039/c2dt $30364 \mathrm{~g}$

Li, Y., Zhang, S., and Song, D. (2013). A luminescent metal-organic framework as a turn-on sensor for DMF vapor. Angew. Chem. Int. Ed. 52, 710-713. doi: $10.1002 /$ anie. 201207610

Manna, S. C., Zangrando, E., Bencini, A., Benelli, C., and Chaudhuri, N. R. (2006). Syntheses, crystal structures, and magnetic properties of $\left[\operatorname{Ln}(\mathrm{III})_{2}\right.$ (Succinate) $\left.)_{3}\left(\mathrm{H}_{2} \mathrm{O}\right)_{2}\right] 0.5 \mathrm{H}_{2} \mathrm{O}[\mathrm{Ln}=\mathrm{Pr}, \mathrm{Nd}, \mathrm{Sm}, \mathrm{Eu}, \mathrm{Gd}$, and Dy] polymeric networks: unusual ferromagnetic coupling in Gd derivative. Inorg. Chem. 45, 9114-9122. doi: $10.1021 /$ ic060807d

Marques, L. F., Correa, C. C., Ribeiro, S. J., Dos Santos, M. V., Dutra, J. D. L., Freire, R. O., et al. (2015). Synthesis, structural characterization, luminescent properties and theoretical study of three novel lanthanide metal-organic frameworks of $\mathrm{Ho}(\mathrm{III}), \mathrm{Gd}(\mathrm{III})$ and $\mathrm{Eu}(\mathrm{III})$ with 2, 5-thiophenedicarboxylate anion. J. Solid State Chem. 227, 68-78. doi: 10.1016/j.jssc.2015. 03.020

Medina-Velazquez, D., Caldiño, U., Morales-Ramirez, A., Reyes-Miranda, J., Lopez, R., Escudero, R., et al. (2019). Synthesis of luminescent terbiumthenoyltriflouroacetone MOF nanorods for green laser application. Opt. Mater. 87, 3-10. doi: 10.1016/j.optmat.2018.08.021

Miyata, K., Konno, Y., Nakanishi, T., Kobayashi, A., Kato, M., Fushimi, K., et al. (2013). Chameleon luminophore for sensing temperatures: control of metal-tometal and energy back transfer in lanthanide coordination polymers. Angew. Chem. Int. Ed. 52, 6413-6416. doi: 10.1002/anie.201301448
Qiongyan, Y., Xiuxia, Z., Maosheng, L., Jianqiao, C., Zhengyuan, Z., Xia, Y., et al. (2008). Syntheses, characterization, and luminescence of two lanthanide complexes $\left.\left[\mathrm{Ln}_{2} \text { (acetate }\right)_{6}\left(\mathrm{H}_{2} \mathrm{O}\right)_{4}\right] \cdot 4 \mathrm{H}_{2} \mathrm{O}(\mathrm{Ln}=\mathrm{Tb}(1), \mathrm{Sm}$ (2). J. Rare Earth 26, 178-184. doi: 10.1016/S1002-0721(08)60061-7

Rahahlia, N., Benmerad, B., Guehria-Laidoudi, A., Dahaoui, S., and Lecomte, C. (2006). Poly [[tetraaqua- $\mu_{4}$-glutarato-cerium(III)] chloride dihydrate]. Acta Crystallogr. E 62, m2145-m2147. doi: 10.1107/S1600536806030741

Rahahlia, N., Benmerad, B., Guehria-Laïdoudi, A., Dahaoui, S., and Lecomte, C. (2007). Three-dimensional ionic frameworks built up from $\mathrm{La}(\mathrm{III})$ and $\mathrm{Ce}(\mathrm{III})$ succinates. J. Mol. Struct. 833, 42-48. doi: 10.1016/j.molstruc.2006.08.029

Rao, X., Song, T., Gao, J., Cui, Y., Yang, Y., Wu, C., et al. (2013). A highly sensitive mixed lanthanide metal-organic framework self-calibrated luminescent thermometer. J. Am. Chem. Soc. 135, 15559-15564. doi: 10.1021/ja407219k

Räsänen, M., Takalo, H., Rosenberg, J., Mäkelä, J., Haapakka, K., and Kankare, J. (2014). Study on photophysical properties of $\mathrm{Eu}(\mathrm{III})$ complexes with aromatic $\beta$-diketones-Role of charge transfer states in the energy migration. J. Lumin. 146, 211-217. doi: 10.1016/j.jlumin.2013.09.076

Reinhard, C., and Güdel, H. U. (2002). High-resolution optical spectroscopy of $\mathrm{Na}_{3}\left[\mathrm{Ln}(\mathrm{dpa})_{3}\right] \cdot 13 \mathrm{H}_{2} \mathrm{O}$ with $\mathrm{Ln}=\mathrm{Er}^{3+}, \mathrm{Tm}^{3+}, \mathrm{Yb}^{3+}$. Inorg. Chem. 41, 1048-1055. doi: 10.1021/ic0108484

Serpaggi, F., and Férey, G. (1998). Hybrid open frameworks (MIL-n). Part 4 Synthesis and crystal structure of MIL-8, a series of lanthanide glutarates with an open framework, $\left.\left[\mathrm{Ln}\left(\mathrm{H}_{2} \mathrm{O}\right)\right]_{2} \mathrm{O}_{2} \mathrm{C}\left(\mathrm{CH}_{2}\right)_{3} \mathrm{CO}_{2}\right]_{3} \cdot 4 \mathrm{H}_{2} \mathrm{O}$. J. Mater. Chem. 8 , 2737-2741. doi: 10.1039/a802713g

Sheldrick, G. M. (2015). Crystal structure refinement with SHELXL. Acta Crystallogr. C Struct. Chem. 71, 3-8. doi: 10.1107/S2053229614024218

Song, Y., Wang, X., Zhang, S., Wang, J., Gao, S., and Chen, S. (2016). Lanthanide-coordination polymers with pyridinedicarboxylic acids: syntheses, structures, and luminescent properties. Z. Anorg. Allg. Chem. 642, 681-691. doi: 10.1002/zaac.201600135

Tan, C., and Wang, Q. (2011). Reversible terbium luminescent polyelectrolyte hydrogels for detection of $\mathrm{H}_{2} \mathrm{PO}_{4}^{-}$and $\mathrm{HSO}_{4}^{-}$in water. Inorg. Chem. 50, 2953-2956. doi: 10.1021/ic102366v

Tsaryuk, V. I., Zhuravlev, K. P., Vologzhanina, A. V., Kudryashova, V. A., and Zolin, V. F. (2010). Structural regularities and luminescence properties of dimeric europium and terbium carboxylates with 1,10 phenanthroline $(\mathrm{CN}=9)$. J. Photochem. Photobiol. A Chem. 211,7-19. doi: 10.1016/j.jphotochem.2010.01.012

Wang, H. M., Liu, H. P., Chu, T. S., Yang, Y. Y., Hu, Y. S., Liu, W. T., et al. (2014). A luminescent terbium coordination polymer for sensing methanol. RSC $A d v$. 4, 14035-14041. doi: 10.1039/C4RA00745J

Wang, J. L., Hou, K. L., Bai, F. Y., Xing, Y. H., and Shi, Z. (2012). Hydrothermal synthesis, crystal structure, and photoluminescence of novel lanthanide metal organic frameworks constructed from 1, 4-benzene-dicarboxylic acid and 1, 2, 4, 5-benzenetetracarboxylic acid as ligands. Struct. Chem. 23, 275-285. doi: 10.1007/s11224-011-9870-4

Wang, Z., Bai, F. Y., Xing, Y. H., Xie, Y., Zeng, X. Q., Ge, M. F., et al. (2010a). Rigid and flexible lanthanide complexes with an infinite Ln-O-Ln framework: synthesis, structure and properties. J. Inorg. Organomet. Polym. Mater. 20, 242-249.

Wang, Z., Xing, Y. H., Wang, C. G., Sun, L. X., Zhang, J., Ge, M. F., et al. (2010b). Synthesis, structure and luminescent properties of coordination polymers with 1, 2-benzenedicarboxylic acid and a series of flexible dicarboxylate ligands. CrystEngComm. 12, 762-773. doi: 10.1039/B916127A

Werts, M. H. (2005). Making sense of lanthanide luminescence. Sci. Prog. 88, 101-131. doi: $10.3184 / 003685005783238435$

Wong, K. L., Law, G. L., Yang, Y. Y., and Wong, W. T. (2006). A highly porous luminescent terbium-organic framework for reversible anion sensing. $A d v$. Mater.18, 1051-1054. doi: 10.1002/adma.200502138

Xiang, S., Bao, D. X., Wang, J., Li, Y. C., and Zhao, X.-Q. (2017). Luminescent lanthanide coordination compounds with pyridine-2, 6-dicarboxylic acid. J. Lumin. 186, 273-282. doi: 10.1016/j.jlumin.2017.02.037

Yan, B., Bai, Y., and Chen, Z. (2005). Synthesis, structure and luminescence of novel 1D chain coordination polymers [ $\mathrm{Ln}$ (isophth)(Hisophth $\left.)\left(\mathrm{H}_{2} \mathrm{O}\right)_{4} \cdot 4 \mathrm{H}_{2} \mathrm{O}\right]_{\mathrm{n}}$ $(\mathrm{Ln}=$ Sm, Dy). J. Mol. Struct.741, 141-147. doi: 10.1016/j.molstruc.2005. 02.004

Zehnder, R. A., Jenkins, J., Zeller, M., Dempsey, C., Kozimor, S. A., Jackson, G., et al. (2018). Conversion of lanthanide glutarate chlorides with interstitial THF 
into lanthanide glutarates with unprecedented topologies. Inorg. Chim. Acta. 471, 502-512. doi: 10.1016/j.ica.2017.11.050

Zhang, C. Z., Mao, H. Y., Wang, Y. L., Zhang, H. Y., and Tao, J. C. (2007). Syntheses of two new hybrid metal-organic polymers using flexible aliphatic dicarboxylates and pyrazine: crystal structures and magnetic studies. J. Phys. Chem. Solids 68, 236-242. doi: 10.1016/j.jpcs.2006.11.001

Zhang, L., Li, B., Su, Z., and Yue, S. (2010). Novel rare-earth(III)-based water soluble emitters for $\mathrm{Fe}(\mathrm{III})$ detection. Sens. Actuat. B Chem. 143, 595-599. doi: 10.1016/j.snb.2009.09.056

Zhao, B., Chen, X. Y., Cheng, P., Liao, D. Z., Yan, S. P., and Jiang, Z. H. (2004). Coordination polymers containing $1 \mathrm{D}$ channels as selective luminescent probes. J. Am. Chem. Soc. 126, 15394-15395. doi: 10.1021/ja047141b

Zhao, L., Liu, Y., He, C., Wang, J., and Duan, C. (2014a). Coordination-driven nanosized lanthanide 'Molecular Lanterns' as luminescent chemosensors for the selective sensing of magnesium ions. Dalton Trans. 43, 335-343. doi: 10.1039/C3DT51900G

Zhao, X. J., Yang, J. H., Liu, Y., Gao, P. F., and Li, Y. F. (2014b). Metalorganic coordination polymers of $\mathrm{Tb}_{2-\mathrm{x}} \mathrm{Eu}_{\mathrm{x}}(\mathrm{BDC})_{3}\left(\mathrm{H}_{2} \mathrm{O}\right)_{\mathrm{n}}$ with tunable fluorescence and smart response toward aldehydes $(0 \leq \mathrm{x} \leq 2, \mathrm{BDC}=1,4$ benzenedicarboxylate). RSC Adv. 4, 2573-2576. doi: 10.1039/C3RA45725G

Zheng, M., Tan, H., Xie, Z., Zhang, L., Jing, X., and Sun, Z. (2013). Fast response and high sensitivity europium metal organic framework fluorescent probe with chelating terpyridine sites for $\mathrm{Fe}^{+}$. ACS Appl. Mater. Interfaces, 5, 1078-1083. doi: $10.1021 / \mathrm{am} 302862 \mathrm{k}$
Zhou, Z., Tan, C., Zheng, Y., and Wang, Q. (2013). Electrochemical signal response for vitamin B1 using terbium luminescent nanoscale building blocks as optical sensors. Sens. Actuat. B Chem. 188, 1176-1182. doi: 10.1016/j.snb.2013. 08.032

Zhu, T., Ikarashi, K., Ishigaki, T., Uematsu, K., Toda, K., Okawa, H., et al. (2009). Structure and luminescence of sodium and lanthanide(III) coordination polymers with pyridine-2, 6-dicarboxylic acid. Inorg. Chim. Acta 362, 3407-3414. doi: 10.1016/j.ica.2009.01.036

Zhuravlev, K. P., Tsaryuk, V. I., Pekareva, I. S., Sokolnicki, J., and Klemenkova, Z. S. (2011). Europium and terbium ortho-, meta-, and para-methoxybenzoates: Structural peculiarities, luminescence, and energy transfer. J. Photochem. Photobiol. A Chem. 219, 139-147. doi: 10.1016/j.jphotochem.2011.02.003

Conflict of Interest: The authors declare that the research was conducted in the absence of any commercial or financial relationships that could be construed as a potential conflict of interest.

Copyright (๑) 2019 Hussain, Chen, Harrison, Elsegood, Ahmad, Li, Muhammad and Awoyelu. This is an open-access article distributed under the terms of the Creative Commons Attribution License (CC BY). The use, distribution or reproduction in other forums is permitted, provided the original author(s) and the copyright owner(s) are credited and that the original publication in this journal is cited, in accordance with accepted academic practice. No use, distribution or reproduction is permitted which does not comply with these terms. 